\title{
4-O-Methylhonokiol Influences Normal Cardiovascular Development in Medaka Embryo
}

\author{
Santu K. Singha ${ }^{1}$, Ilias Muhammad ${ }^{2}$, Mohamed Ali Ibrahim ${ }^{2,3}{ }^{-}$, Mei Wang ${ }^{2}{ }^{(0}$, \\ Nicole M. Ashpole ${ }^{1,2}$ and Zia Shariat-Madar 1,2,4,* \\ 1 Department of Biomolecular Sciences, Division of Pharmacology, University of Mississippi, University, \\ MS 38677, USA; sksingha@go.olemiss.edu (S.K.S.); nmashpol@olemiss.edu (N.M.A.) \\ 2 The National Center for Natural Products Research, Research Institute of Pharmaceutical Sciences, \\ University of Mississippi, University, MS 38677, USA; milias@olemiss.edu (I.M.); \\ mmibrahi@olemiss.edu (M.A.I.); meiwang@olemiss.edu (M.W.) \\ 3 Chemistry of Natural Compounds Department, National Research Centre, Dokki-Giza 12622, Egypt \\ 4 Light Microscopy Core, University of Mississippi, University, MS 38677, USA \\ * Correspondence: madar@olemiss.edu; Tel.: +662-915-5150
}

Received: 14 December 2018; Accepted: 27 January 2019; Published: 29 January 2019

\begin{abstract}
Although 4-O-Methylhonokiol (MH) effects on neuronal and immune cells have been established, it is still unclear whether $\mathrm{MH}$ can cause a change in the structure and function of the cardiovascular system. The overarching goal of this study was to evaluate the effects of $\mathrm{MH}$, isolated from Magnolia grandiflora, on the development of the heart and vasculature in a Japanese medaka model in vivo to predict human health risks. We analyzed the toxicity of $\mathrm{MH}$ in different life-stages of medaka embryos. MH uptake into medaka embryos was quantified. The $\mathrm{LC}_{50}$ of two different exposure windows (stages 9-36 (0-6 days post fertilization (dpf)) and 25-36 (2-6 dpf)) were $5.3 \pm 0.1 \mu \mathrm{M}$ and $9.9 \pm 0.2 \mu \mathrm{M}$. Survival, deformities, days to hatch, and larval locomotor response were quantified. Wnt 1 was overexpressed in $\mathrm{MH}$-treated embryos indicating deregulation of the Wnt signaling pathway, which was associated with spinal and cardiac ventricle deformities. Overexpression of major proinflammatory mediators and biomarkers of the heart were detected. Our results indicated that the differential sensitivity of $\mathrm{MH}$ in the embryos was developmental stage-specific. Furthermore, this study demonstrated that certain molecules can serve as promising markers at the transcriptional and phenotypical levels, responding to absorption of $\mathrm{MH}$ in the developing embryo.
\end{abstract}

Keywords: cardiomyogenesis; factor VII; factor X; inflammation; thrombosis; vasculogenesis; herbal medicine

\section{Introduction}

Magnolia bark extract has been used as a component of dietary supplements and cosmetic products [1]. One specific compound found in Magnolia species, 4-O-Methylhonokiol (MH), is recognized to have multifunctional activities both in vitro and in vivo, similarly to other honokiol analogs [2,3]. Magnolias appear to naturally produce a significant amount of these biphenyl-type neolignan compounds, many of which show tissue specific distribution [4]. $\mathrm{MH}$ is expressed throughout the plant, with high amounts found in the leaves and seeds [5], whereas honokiol with its isomer magnolol are largely limited to the bark [6]. $\mathrm{MH}$ and 2-O-Methylhonokiol are isomers [7]. The optimal ratio of these two isomers and their mechanism of synthesis have not been fully characterized. Moreover, the effects of $\mathrm{MH}$ on the cardiovascular system remain poorly understood. Due to its low hydrophilicity, MH exhibits poor pharmacokinetics [8], which may lead to 
increased accumulation in the organs of the body. Some evidence has suggested beneficial effects of $\mathrm{MH}$, as it has been associated with anti-inflammatory [9], anti-osteoclastogenic, anti-oxidative [10,11], and neuroprotective [12] effects. Considering the apparent non-specificity of these effects, it is likely that $\mathrm{MH}$ has low targeting efficacy and exerts its cellular protective properties through a wide range of mechanisms. In contrast to the observed beneficial effects, the co-treatment of compounds with $\mathrm{MH}$ counterparts, both magnolol and honokiol, can exert synergistic cytotoxicity [13]. The incongruity between the protective and detrimental effects of $\mathrm{MH}$ thus far in the literature highlights the importance of understanding how $\mathrm{MH}$ or other compounds extracted from magnolia affect the development and function of tissues and organs, like the cardiovascular system.

Both angiogenesis and vasculogenesis (de novo blood vessel formation from embryonic precursors) have many features in common, and impairment of these processes can in turn cause damage to organs and influence blood circulation. We aim to identify exposure windows, which can provide insight into the potentially toxic effects of $\mathrm{MH}$ on the development of the heart, angiogenesis, and vasculogenesis, beyond its other potential action on multiple sites through different toxicity pathways. Identifying the critical stage of MH-induced cardiovascular toxicity lays down a basis for further elucidation of an adverse outcome pathway for $\mathrm{MH}$ and provides a starting point for future studies on the mechanisms of $\mathrm{MH}$ toxicity.

Due to its inherent low concentration in plant extracts containing honokiol and magnolol, $\mathrm{MH}$ has not been fully characterized. $\mathrm{MH}$, like propofol, has a phenol ring, which produces side effects causing hypertension and altering both heartbeat and heart rate. Since magnolia bark extract is gaining widespread popularity as a preventive and alternative to medical treatments [14,15], it is vital to understand the molecular mechanisms of $\mathrm{MH}$ and characterize whether it causes embryotoxic and teratogenic effects in the cardiovascular system in a variety of vertebrates. By accounting for heterogeneities typical of Japanese medaka (Oryzias latipes), which shares 58\% homology with its human counterpart, our first vertebrate model for the embryonic lethality of $\mathrm{MH}$ enables us to investigate the effects of MH on the embryo's developing heart and deformities, as well as alterations in inflammatory and parameters of coagulation.

In this study, we assessed the toxicity of $\mathrm{MH}$ in different life-stages of the medaka cardiovascular system. We hypothesized that the differential susceptibility of the stage-specific embryo might identify critical exposure windows to $\mathrm{MH}$, which could in turn produce lethal and sublethal thresholds for toxicity because of differences in uptake of $\mathrm{MH}$ and subsequent internal concentrations.

\section{Results}

\subsection{Toxicity of $M H$ in Medaka Embryo}

The toxicity of MH exposure on medaka was assessed at various stages of development (see $\mathrm{MH}$-treatment in Materials and Methods section). While $10 \mu \mathrm{M} \mathrm{MH}$ was not toxic to embryos after $48 \mathrm{~h}$, it caused $70 \%$ mortality within $96 \mathrm{~h}$. A full concentration-response analysis of toxicity following six days of $\mathrm{MH}$ exposure time point revealed significant mortality of $\mathrm{MH}$-treated medaka embryo/larvae $\left(\mathrm{LC}_{50}=5.3 \pm 0.1 \mu \mathrm{M}\right)$ (Figure 1A). Larval toxicity was also evident, with the most common effects being spine malformations and edema. Observation of overall mortality with increasing concentrations over time revealed a reduction in larval survivability following exposure to concentrations of $2 \mu \mathrm{M} \mathrm{MH}$ and higher (Figure 1B). Some spinal deformities were observed in the larvae (Appendix A, Figure S1 under Supplementary Materials) which were associated with $5 \mu \mathrm{M}$ and $10 \mu \mathrm{M} \mathrm{MH}$. Embryos exposed to $10 \mu \mathrm{M}$ MH showed delayed growth and high mortality rates during late larval- and juvenile-life stages. 
A
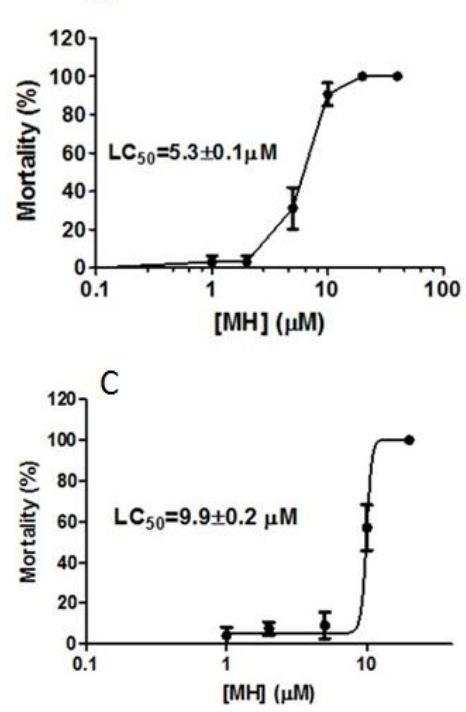

B

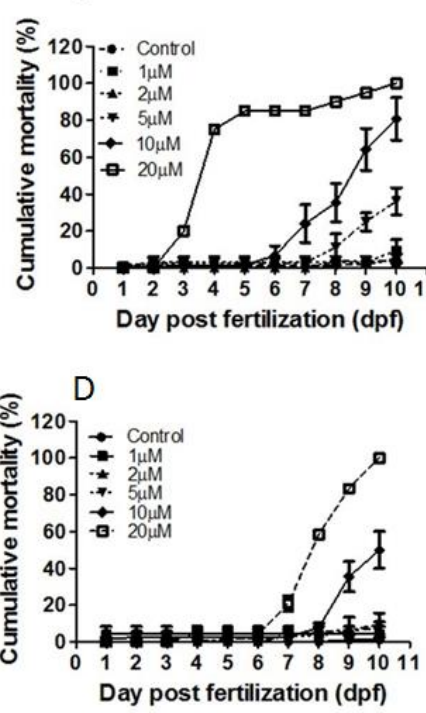

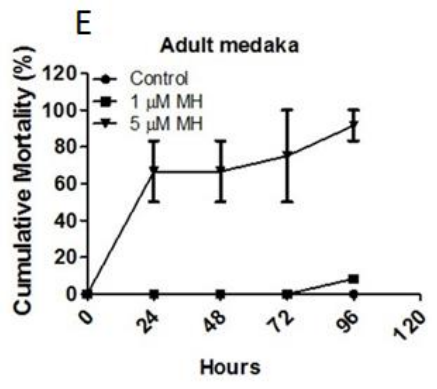

Figure 1. Cumulative mortality of medaka embryos. Embryos were exposed to 1, 2, 5, 10, and $20 \mu \mathrm{M}$ 4-O-Methylhonokiol (MH) for 0-6 days post fertilization (dpf) (A,B) or 2-6 dpf (C,D). (A) Embryos were treated with $\mathrm{MH}$ for six days from hour 5 , and the $\mathrm{LC}_{50}$ was calculated based on mortality observed at $10 \mathrm{dpf}$. (B) Cumulative mortality of all embryos until $10 \mathrm{dpf}$ treated with various concentrations of $\mathrm{MH}$ for 0-6 dpf. (C) Embryos were treated with $\mathrm{MH}$ for four days from $2 \mathrm{dpf}$ and the $\mathrm{LC}_{50}$ was calculated based on mortality observed at $10 \mathrm{dpf}$. (D) Cumulative mortality until $10 \mathrm{dpf}$ of all embryos treated with various concentrations of $\mathrm{MH}$ for 2-6 dpf. The $\mathrm{LC}_{50}$ was calculated by log transformed data using nonlinear regression (curve-fit) (GraphPad Prism). Each value represents mean \pm SEM ( $n=12$, replicated five times). (E) The relationship between MH concentration and mean adult medaka mortality. Eighteen male medakas were randomly divided into three groups $(n=6)$. They were exposed to 1 or $5 \mu \mathrm{M} \mathrm{MH}$, and monitored for $96 \mathrm{~h}$. Controls were exposed to $0.02 \%$ DMSO.

A second batch of embryos exposed to $\mathrm{MH}$ later in development (2-6 dpf) also exhibited concentration-dependent toxicity $\left(10 \mathrm{dpf}, \mathrm{LC}_{50}=9.9 \pm 0.2 \mu \mathrm{M}\right)$ (Figure 1C). Like the first batch of embryos, survivability was significantly reduced in later-staged larvae exposed to 10 and $20 \mu \mathrm{M}$ (Figure 1D). There was a direct relationship between the changes in $\mathrm{MH}$ concentration and changes in hatching efficiency. Behavioral alterations such as difficulty in swimming and equilibrium loss were seen with both $5 \mu \mathrm{M} \mathrm{MH}$ and $10 \mu \mathrm{M}$ MH. However, while termination from $\mathrm{MH}$ treatment allowed $5 \mu \mathrm{M}$ MH-treated embryos to recover normal behavior, stopping $\mathrm{MH}$ treatment at $6 \mathrm{dpf}$ from hour 5 was ineffective in the $10 \mu \mathrm{M}$ MH group. The control group treated with DMSO, ranging from 0.02 to $0.04 \%$, exhibited normal embryo development and normal hatching. Embryo mortality for this group was always below $10 \%$, contrasting clearly with the experimental groups. The sensitivity of adult medaka to $\mathrm{MH}$ toxicity was then assessed. Exposure of $5 \mu \mathrm{M} \mathrm{MH}$ in adults caused $65 \%$ mortality within $24 \mathrm{~h}$, whereas both the control group and fish exposed to $1 \mu \mathrm{M} \mathrm{MH}$ survived (Figure 1E). The survival time of $5 \mu \mathrm{M} \mathrm{MH}$ was significantly less than that of $1 \mu \mathrm{M} \mathrm{MH}$-immersed adult medaka. This result demonstrates that $5 \mu \mathrm{M}$ MH reduces survivability in the adult medaka model and further underscores its importance for additional health-related research.

The membrane penetration properties of $\mathrm{MH}$ on the medaka chorion are unknown. Although the chorion of the egg acts as a barrier within the embryo, the $80 \%$ mortality of embryos indicated an incorporation of $\mathrm{MH}$ into the egg. Mass spectrometry analysis of $\mathrm{MH}$ levels in conditioned growth media from the medaka revealed that the concentrations of $\mathrm{MH}$ decreased to non-detectable levels from time $0 \mathrm{~h}$ to $24 \mathrm{~h}$ (Figure 2A,B). However, a second molecule with a retention time of $2.628 \mathrm{~min}$ was present following $24 \mathrm{~h}$ incubation when MS was operated in scan mode (Figure 2C). Since the molecular and biochemical basis of formation of this molecule from $\mathrm{MH}$ is unknown, the identity of this unknown molecule was not characterized. Nevertheless, incubation of embryos with $\mathrm{MH}$ for $24 \mathrm{~h}$ 
led to $100 \%$ MH disappearance from the media (Figure 2D), suggesting either uptake of MH into the fish and/or degradation of the molecule.

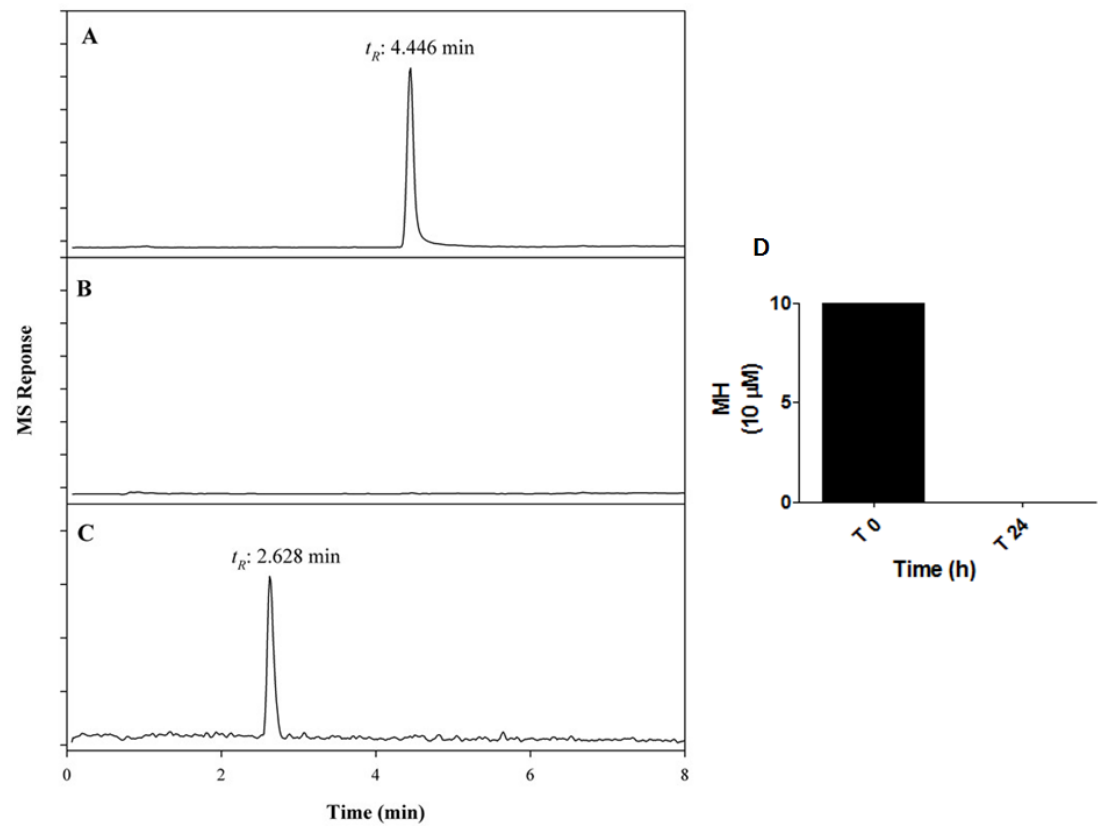

Figure 2. Quantification of $\mathrm{MH}$ uptake by medaka embryos by liquid chromatography-mass spectrometry (MS). This figure is a typical MS profile for the analysis of $10 \mu \mathrm{M}$ MH uptake following $24 \mathrm{~h}$-incubation with embryos, and maintained at $26 \pm 1{ }^{\circ} \mathrm{C}$. The amount of $\mathrm{MH}$ disappearance from the conditioned media was measured at time $0 \mathrm{~h}$ and time $24 \mathrm{~h}$. Selected ion monitoring (SIM) at $m / z$ 281 shows signals for $\mathrm{MH}$ at time $0 \mathrm{~h}$ (A) and time $24 \mathrm{~h}$ (B). (C) The unknown molecule in MS scan mode. (D) The amount of disappearance of $\mathrm{MH}$ following $24 \mathrm{~h}$ incubation with embryo.

\subsection{Exposure to MH during Early Development Affects Cardiovascular Structure and Function}

Cardiovascular changes in response to $\mathrm{MH}$ were then assessed. We demonstrated here that $\mathrm{MH}$ treatment resulted in reduced blood flow which peaked at around an $80 \%$ decrease with $10 \mu \mathrm{M} \mathrm{MH}$ at the end of the 0-6 dpf treatment session (Figure 3A). The reductions in blood flow were associated with corresponding changes in blood vessel occlusion (Figure 3B). Reduced blood flow (Figure 3C) and blood vessel occlusion (Figure 3D) were noticeable in the 2-6 dpf embryos also, at the same concentrations as compared to those of control embryos from day six (stages 36-38).

As shown in Figure 4A, the resting heart rate for both the control and DMSO-treated $(0.02 \%)$ embryos increased with development. MH-treated embryos had lower heart rates than the control group at three-days and six-days post-treatment. $\mathrm{MH}$ treatment was effective in reducing the heart-beat of late embryos ( $6 \mathrm{dpf})(p \leq 0.05, n=27)$ by $9 \%$, suggesting $\mathrm{MH}$ influences the normal functioning of the heart. High-speed time-lapse analysis of the heartbeat showed that bradycardia occurred in the 0-6 day embryos treated with $10 \mu \mathrm{M} \mathrm{MH}$ when treatments were initiated early (from hour 5) (Figure 4B,C; see videos for better visualization of the differences in heart malfunction between the control (video 1) and MH-treated embryo (video 2) in Appendix B under Supplementary Materials). The average heart rate and blood flow for the $10 \mu \mathrm{M} \mathrm{MH}$-treated embryos were lower than for the DMSO-treated controls. 

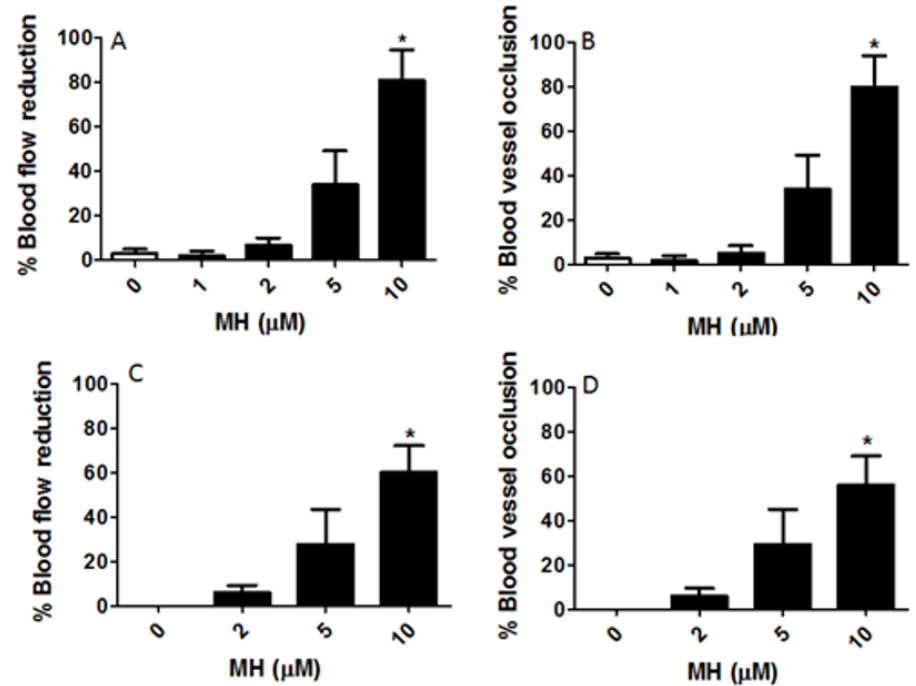

Figure 3. Reduction of blood flow and vascular occlusion by MH. Embryos were exposed to 1, 2, 5, and $10 \mu \mathrm{M}$ MH from $5 \mathrm{~h}$ post fertilization (hpf) to $6 \mathrm{dpf}(0-6 \mathrm{dpf},(\mathbf{A}, \mathbf{B}))$ or from $2 \mathrm{dpf}$ to $6 \mathrm{dpf}(2-6 \mathrm{dpf},(\mathbf{C}, \mathbf{D}))$. This figure showed that the reduction in blood flow was proportionally correlated with blood vessel occlusion. (A) Blood flow was observed on days 2, 3, 4, 5, and 6 to verify the duration of the reduction of blood flow. This panel exemplifies the percent reduction in blood flow until $10 \mathrm{dpf}$ in response to various concentrations of $\mathrm{MH}$ for 0-6 dpf. (B) This panel shows percent occlusion following $\mathrm{MH}$ treatment. During the treatment, blood flow was significantly reduced compared to the control immediately after occlusion. (C) Thirty-two embryos ( $2 \mathrm{dpf}$ ) were randomly divided into four groups $(n=8)$. Embryos were treated with the indicated concentrations of MH and $0.02 \%$ DMSO (control) in embryo medium and were maintained at $26 \pm 1{ }^{\circ} \mathrm{C}$ for 4 days. This figure shows reduced blood flow in $\mathrm{MH}$-treated embryos (2-6 dpf). (D) This figure demonstrates a blockage that prevents normal flow of blood for the MH-treated embryos exposed to various concentrations of MH from $2 \mathrm{dpf}$ to $6 \mathrm{dpf}$. Each bar represents data pooled from 4-5 independent experiments. Statistical analysis was performed by one-way analysis of variance (ANOVA) followed by Tukey's post-hoc multiple comparison test. $p<0.05$ was considered as significant. The asterisk $(*)$ indicates values significantly different from the control.

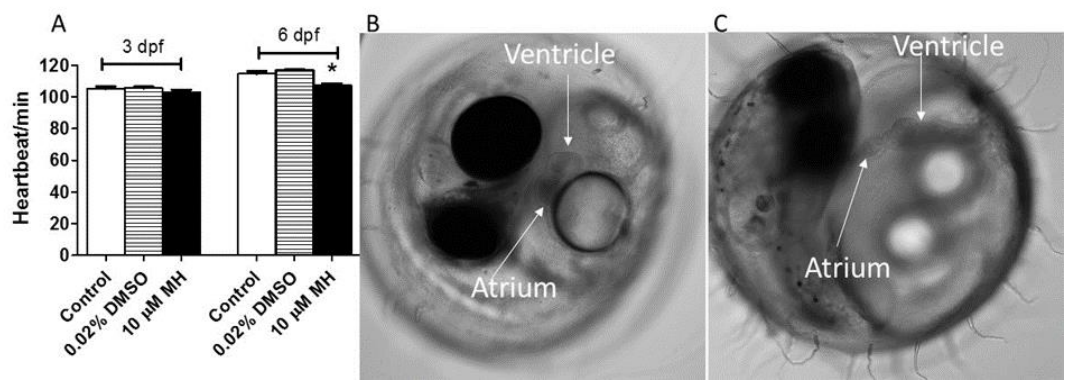

Figure 4. $\mathrm{MH}$ is responsible for the defect in cardiac function in vivo. Embryos were exposed to $10 \mu \mathrm{M}$ $\mathrm{MH}$ or $0.02 \%$ DMSO (which was used as solvent in the treated condition) as the control from $5 \mathrm{hpf}$ to $6 \mathrm{dpf}$. Heartbeat, blood flow, and heart structure were evaluated. (A) Heart beat was recorded and expressed as beats per min. Bar graphs of results obtained by counting heart beats. Results are given as the mean percentage of heart beat $\pm \operatorname{SEM}$ ( $n>8$ embryos for each condition). Statistical analysis was performed by one-way ANOVA followed by Tukey's post-hoc multiple comparison test $(p<0.05)$. (B) Representative image of heart function in the control. (C) Representative bright field images of $\mathrm{MH}$-induced heart ventricle malfunction in embryos treated with $10 \mu \mathrm{M} \mathrm{MH}$ for six days from hour 5 . See videos for better visualization of the differences in heart malfunction between the control (video 1) and $\mathrm{MH}$-treated embryo (video 2). Images were acquired on a Nikon TI2-E inverted microscope with a white light LED illuminator and a sCMOS Cooled Monochrome Camera. Videos were captured using a Nikon Elements automated acquisition device. 


\subsection{MH Is Implicated in Cardiovascular Dysfunction}

To examine the mechanism of these vascular changes, expression levels of three key coagulation factors, factor XI (FXI, a protease of intrinsic pathway), factor VII (FVII, a protease of extrinsic pathway), and factor $X$ (FX, a protease of common pathway) were quantified (Figure 5A). These factors are essential for hemostasis and indispensable for thrombosis. FXI, FX, and FVII circulate in the blood in zymogen forms. Activation of them leads to the formation of blood clots. As shown in Figure 5, these three protease transcripts were significantly ( $p \leq 0.05, n=100$, replicated four times) elevated in embryos treated with $10 \mu \mathrm{M}$ MH for six days from hour 5 .

Since $\mathrm{MH}$ reduced blood flow (Figure 3A,C), we hypothesized that the reduced blood flow activated the endothelium to synthesize and release tissue plasminogen activator (tPA, a fibrinolytic peptide) and plasminogen activator inhibitor 1 (PAI-1, a prothrombotic peptide) and thus decrease the ratio of $\mathrm{tPA} / \mathrm{PAI}-1$, ultimately promoting thrombosis. PAI-1 cDNA product was significantly elevated at the mRNA level with $10 \mu \mathrm{M} \mathrm{MH}$, while tPA and endothelin B mRNA levels were not altered (Figure 5A). However, the ratio of the steady-state tPA/PAI-1 mRNA was significantly decreased in the embryos, suggesting increased levels of fibrin fragments, as previously described [16]. We measured the quantitative expression pattern of urokinase plasminogen activator (uPA) in 0-6 day embryos treated with $10 \mu \mathrm{M} \mathrm{MH}$ from hour 5. uPA mRNA levels were significantly increased (Figure 5A). To confirm that vascular endothelial cells are activated in response to $\mathrm{MH}$, we examined the expression profiles of endothelin B receptors that are located primarily in vascular endothelial cells and angiotensin II type 1 receptor-associated protein (ATRAP), which is highly expressed in the kidney [17] and large vessel [18]. Vascular expression of ATRAP was significantly enhanced in response to MH (Figure 5A). Taken together, the data of Figure 5 demonstrated a previously unrecognized effect of $\mathrm{MH}$ on the control of the cardiovascular system and suggested that FXI, FX, FVII, PAI-1, uPA, and ATRAP are targets of $\mathrm{MH}$.
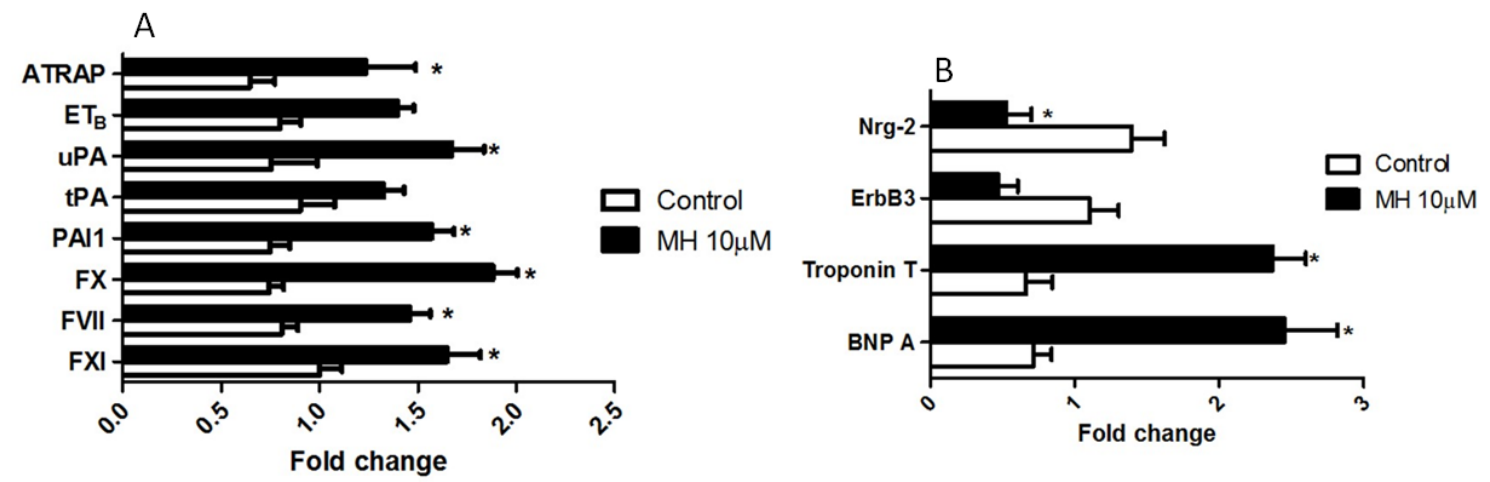

Figure 5. Embryos treated with $\mathrm{MH}$ lead to altered cardiac biomarker gene expression and altered expression of genes involved in thrombosis, fibrinolysis, and vascular tone. Real-time RT-qPCR was performed on total RNA isolated from each group of embryos using described primers in Table 1 leading to the amplification of the target gene. (A) RT-qPCR analysis of factor XI (FXI), factor VII (FVII), factor X (FX), plasminogen activator inhibitor 1 (PAI-1), tissue plasminogen activator (tPA), urokinase plasminogen activator ( $\mathrm{uPA})$, endothelin $\mathrm{B}(\mathrm{ETB})$, and angiotensin type 1 receptor associated protein (ATRAP) isolated from control and MH-treated embryos. (B) RT-qPCR analysis of natriuretic peptide A, Troponin T, ErbB3, and Nrg2. Data were normalized to the eukaryotic elongation factor 1-alpha $(\mathrm{eEf} 1 \alpha)$ polymerase chain reaction signal. Each value represents mean $\pm \operatorname{SEM}(n=100$, replicated four times). ${ }^{*}$ indicates a value is significant versus the respective control group $(p<0.05)$.

To further confirm that $\mathrm{MH}$ influences the normal functioning of the heart, we measured the expression patterns of heart development-related genes. Controls were exposed to 0.01\% DMSO for the RT-qPCR study. After treatment with $10 \mu \mathrm{M} \mathrm{MH}$, the embryos showed highly up-regulated expression of brain natriuretic peptide A and troponin T (Figure 5B). Further investigations were performed to explore 
the effect of $\mathrm{MH}$ on Nrg-2 and ErbB3, the molecules involved in the synthesis of acetylcholine at the neuromuscular junction [19]. Nrg-2, a cardiac chamber maturation marker, and ErbB3, which is involved in proper heart morphogenesis and function, were attenuated (Figure 5B). These findings conferred that the cardioprotective property of the Nrg molecule was compromised in the presence of $\mathrm{MH}$.

\subsection{MH Possesses the Proinflammatory and Pro-Oxidative Properties}

We looked into the effect of $\mathrm{MH}$ on the expression levels of catalase, glutathione peroxidase (GPX), glutathione-S-transferase (GST), and superoxide dismutase (SOD) (Figure 6). Forkhead boxO1 (FoxO1) was overexpressed with 0-6 dpf MH exposure beginning from hour 5 (Figure 6). Catalase, GPX, and GST mRNAs were significantly overexpressed, whereas SOD mRNA was not statistically significant (Figure 6). This finding suggested that MH-dependent increased expression of these anti-oxidant enzymes in the embryo was a mechanism by which they could eliminate excess reactive oxygen species (ROS). Since the Wnt/ $\beta$-catenin signaling pathway is capable of regulating inflammatory cell migration and macrophage phenotypes in zebrafish [20], we then assessed the expression profiles of tissue necrosis factor-alpha (TNF- $\alpha$ ) and interleukin 1 beta (IL-1 $\beta$ ) (Figure 6). Expression analysis showed significant upregulation of IL- $1 \beta$ and TNF- $\alpha$ in MH-treated embryos at the transcription level (Figure 6). This observation suggests that the overexpression of FoxO1 might cause a decrease in endothelial cell sprouting and migration, as seen in a previous report [21]. On the basis of these results, MH appears to possess proinflammatory properties at the embryo level.

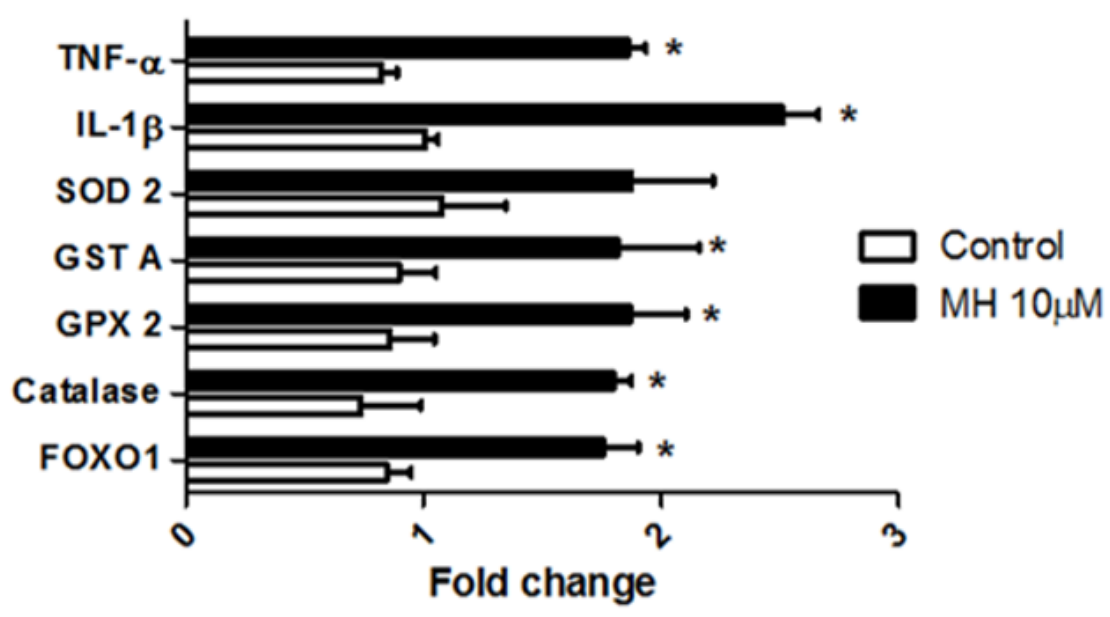

Figure 6. Embryos treated with $\mathrm{MH}$ lead to altered expression of genes involved in cell regulation, oxidative stress, and inflammation. Real-time RT-qPCR was performed on total RNA isolated from each group of embryos using described primers in Table 1 leading to the amplification of the target gene. RT-qPCR analysis of FoxO1, catalase, glutathione peroxidase (GPX2), glutathione-s-transferase (GSTA), superoxide dismutase 2 (SOD-2), Interleukin 1 beta (IL-1 $\beta$ ), and tissue necrosis factor-alpha (TNF- $\alpha$ ) isolated from control and $\mathrm{MH}$-treated embryos. Data were normalized to the eEf1 $\alpha$ polymerase chain reaction signal. Each value represents mean $\pm \operatorname{SEM}(n=100$, replicated four times). Statistical analysis was performed by two-way ANOVA followed by post-hoc Bonferroni test. * indicates values which are significant versus the respective control group $(p<0.05)$.

\subsection{MH Reduces the Normal Hatching Process of Medaka Embryos}

We hypothesized that decreased heart rate might reduce the embryos' activity, leading to a reduction in the distribution of nutrients and both coagulation and hatching enzymes, as has been previously suggested [22]. To test this hypothesis, we explored the effects of $\mathrm{MH}$ on hatching. MH caused a reduction in hatching in embryos exposed to $10 \mu \mathrm{M} \mathrm{MH}$ starting from the hours immediately after fertilization (Figure 7A) or starting two days later (Figure 7B). Our findings demonstrate that $\mathrm{MH}$ can 
influence both early and late developmental stages of medaka, leading to reduced hatchability of eggs at higher concentrations.
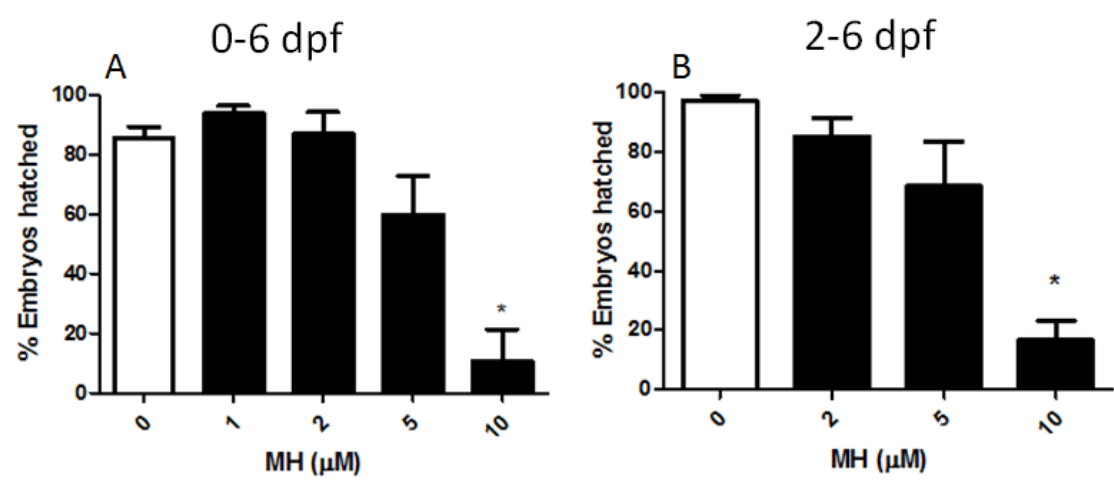

Figure 7. The effectiveness of $\mathrm{MH}$ at different concentrations at altering hatching of medaka embryos. Under pure culture conditions, embryo hatching efficacy was altered by increasing concentrations of MH. (A) Embryos were treated with increasing concentrations of $\mathrm{MH}$ for six days from hour 5 (0-6 dpf). $\mathrm{MH}$ concentrations of $5 \mu \mathrm{M}$ and higher were required to cause a delay in hatching. Hatchability of embryos from six days $\mathrm{MH}(10 \mu \mathrm{M})$-treatment was significantly decreased in comparison to untreated controls until $10 \mathrm{dpf}$. The external differences in appearance of the newly hatched control frys on day ten and the $10 \mu \mathrm{M}$ MH-treated embryos were significantly obvious. (B) Embryos were treated with increasing concentrations of $\mathrm{MH}$ for four days from stage 25 (2-6 dpf). MH concentrations of $10 \mu \mathrm{M}$ and higher were required to significantly cause a delay in hatching. Results are given as the mean percentage of hatching efficiency \pm SEM $(n>8$ embryos for each condition). Statistical analysis was performed by one-way ANOVA followed by Tukey's post-hoc multiple comparison test. $p<0.05$ was considered as significant. The asterisk $\left.{ }^{*}\right)$ indicates values significantly different from the control.

\subsection{MH Regulates Wnt/B-Catenin Pathway during Cardiomyogenesis}

Transcript levels of several Wnt/ $\beta$-catenin signaling pathway proteins were altered in embryos treated with $10 \mu \mathrm{M}$ MH for six days (Figure 8). Wnt 1 mRNA expression was significantly increased by MH. As shown in Figure 8, control and MH-treated embryos had similar levels of TGF- $\beta 2$ mRNA expression, suggesting that $\mathrm{MH}$ could potentially promote cardiac fibrogenesis through the Wnt signaling pathway.

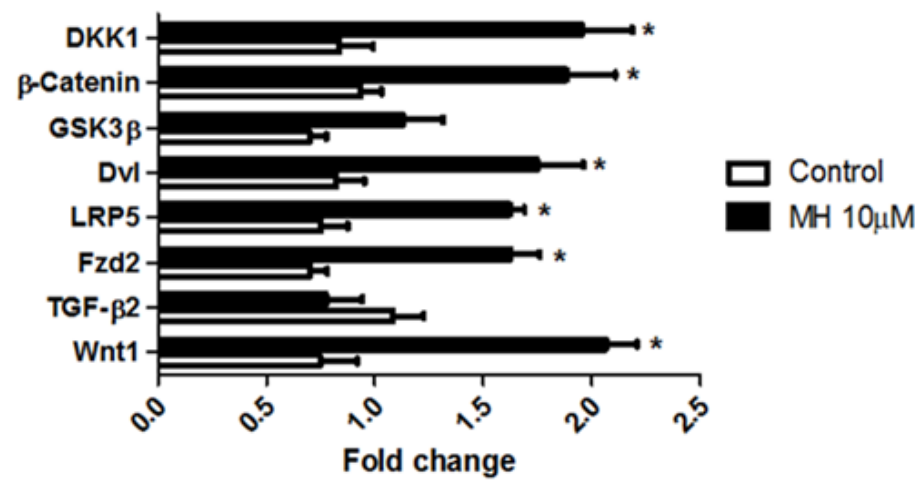

Figure 8. MH controls the Wnt signal transduction pathway, a main regulator of development. Real-time RT-qPCR was performed on total RNA isolated from each group of embryos using described primers in Table 1, leading to the amplification of the target gene. RT-qPCR analysis of Wnt 1, transforming growth factor beta 2 (TGF- $\beta 2$ ), frizzled 2 (Fzd2), low-density lipoprotein receptor-related protein 5 (LRP5), dishevelled (Dvl), glycogen synthase kinase 3 beta (GSK-3 $\beta$ ), $\beta$-catenin, and dickkopf 1 (DKK1) isolated from the control and MH-treated embryos. Each value represents mean $\pm \operatorname{SEM}(n=100$, replicated four times). Statistical analysis was performed by two-way ANOVA followed by post-hoc Bonferroni test. * indicates values which are significant versus the respective control group $(p<0.05)$. 
High expression levels of Fzd 2 (Wnt 1 receptor), LRP5 (Wnt 1 co-receptor), and Dvl were observed in MH-treated embryos, but there was no difference in expression levels of glycogen synthase kinase-3 beta (GSK-3 $\beta$ ), which is involved in the suppression of the Wnt $/ \beta$-catenin and subsequent degradation of beta-catenin (Figure 8). A significant increase was apparent in levels of $\beta$-catenin transcript of the MH group. Increased $\beta$-catenin is implicated in ventricular myocyte proliferation control, while its decrease leads to differentiation [23]. Thus, MH might inhibit cardiac differentiation via increased endogenous $\beta$-catenin-mediated signaling during normal cardiac development.

Expression levels of dickkopf 1 (DKK1, a secreted Wnt/ $\beta$-catenin pathway inhibitor) in the $\mathrm{MH}$-treated embryos were significantly higher compared to those of the control group (Figure 8). MH-induced Wnt 1 overexpression enhanced the expression of several downstream molecules involved in heart development. These molecules included Fzd 2, Dvl, LRP5, $\beta$-catenin (a downstream target of LRP5), and DKK1. Collectively, MH clearly influenced the Wnt/ $\beta$-catenin signaling pathway, which had roles during various stages of cardiac development.

\subsection{MH Prolongs Swimming Duration}

The locomotion of embryos exposed to a sublethal concentration of $\mathrm{MH}$ was assessed two days post hatching (Figure 9). Control fish showed clear response to the light-dark cycle while MH treatment blunted this locomotor response (Figure 9).

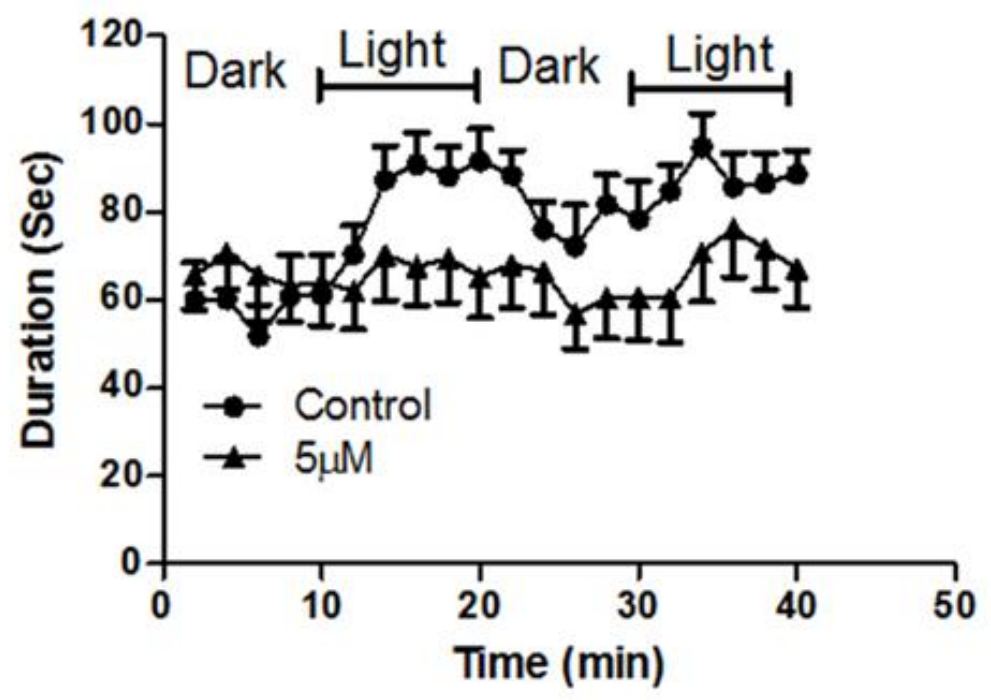

Figure 9. MH altered larvae' locomotor responses to light and dark stimuli. Medaka larvae (2 days post hatching (dph)) were monitored for 40 min (0-10 min dark, 10-20 min light, 20-30 min dark, 30-40 min light) using a ViewPoint Zebrabox. Duration of movements was measured at 2 min intervals at a velocity of $\geq 2 \mathrm{~mm} / \mathrm{s}$. Larvae were treated with $5 \mu \mathrm{M}$, a sub-lethal concentration; $\mathrm{MH}$ and their activity were measured in $10 \mathrm{~min}$ windows at the indicated time points. No significant (two-tailed $t$-test, $p<0.05$ ) increase in activity in MH-treated larvae (solid closed triangles, $n=14$ ) was noted for the time window during the light-cycle compared to baseline levels and that of the control group (solid closed circles, $n=16$ ). Each datum represents mean \pm SEM of 16 observations.

\section{Discussion}

Much of our knowledge of the function of MH has been extrapolated from its analogs' action and its usage in the form of plant extracts in health and disease, which could provide a bias leading to untoward side-effects. Compounds/drugs often have diverse and/or mixed effects from one organ to another as well as across different disease states. The present study was aimed at demonstrating the effects of $\mathrm{MH}$ and to establish its possible therapeutic utility. Many plant extracts have MH-like molecules, but the effects of $\mathrm{MH}$ on cardiogenesis and neurogenesis have not been comprehensively studied in contrast to cancer and inflammation. With increasing interest in honokiol related compound 
therapy, and their usage as supplements in diets and cosmetics, investigations were performed to answer the following questions: (1) What was the effect of $\mathrm{MH}$ on known genes involved in cardiac development and function in medaka embryos? (2) What were the morphological and physiological effects of daily MH treatment in medaka embryos? (3) What was the effect on embryonic survival and hatching of subjecting medaka embryos at different stages of cardiovascular development to various concentrations of MH for different lengths of time? (4) Was MH a prothrombotic agent? (5) What was the impact of sublethal concentration of $\mathrm{MH}$ on locomotion?

Fertilized eggs of medaka at two developmental stage windows (9-36 or 25-36) were exposed to increasing concentrations of $\mathrm{MH}$ in an embryo medium. Our data showed that $\mathrm{MH}$-induced embryonic fatality was developmental-stage-specific. The embryos were more sensitive to $\mathrm{MH}$ at early stages of development (9-25) than in late stages of development. MH-treated embryos exhibited cardiovascular complications with a spectrum ranging from reduced blood flow to blood vessel occlusion, thrombus formation, and slow heart rate.

In recent years, it has become apparent that the Wnt/ $\beta$-catenin pathway (Wnt signaling pathway) is essential for the regulation of numerous genes in embryogenesis [24], adult cell biology [25], tissue homeostasis [26], and disease [27]. The canonical (known as the morphogen pathway) signaling of this pathway is capable of upregulating the expression of a wide range of genes, which have roles in giving rise to the majority of cardiomyocytes [28]. Targeted pathways related to Wnt include cardiac differentiation [29] and cardiac remodeling [30]. Increased activated Wnt signaling has been recognized as a major pathomechanism in heart and blood vessels [31]. Uncontrolled activation of the Wnt signaling pathway has been implicated in the pathogenesis of cardiovascular disease [32] and inflammation [33]. The Wnt/ $\beta$-catenin pathway not only has a major role in cardiovascular development, but it has been also proven that a specific isoform of Wnt, Wnt-5A, functions in the process of neurogenesis and establishment of functional connectivity [34], suggesting its tissue specificity. To understand why chronic MH treatment may have undesirable effects in embryos, we investigated the effect of $\mathrm{MH}$ on the components of the Wnt signaling pathway and its downstream targeted molecules, which may offer novel mechanistic insights that could pave the way to enhancing its clinical utility.

Due to difficulties in the pharmacological approach and the absence of antibodies, quantification of gene expression profiling of medaka cardiovascular tissues was the alternative approach to clarify the role(s) MH plays in embryogenesis, and to assess the clinical utility of MH. MH-treated embryos showed increased expression of the Wnt 1 gene (Figure 8). This deregulation of the Wnt signaling pathway prompted us to target key members of this pathway, which had exhibited distinct temporal and spatial profiles of expression during normal embryogenesis, post-surgery [35], and disease states [36]. It has been established that when both the Fzd receptor and LRP5/6 form a complex with Wnt ligands, the Wnt/ $\beta$-catenin signaling pathway is activated [37]. Thus, we assessed the effect of MH on the expression profile of Fzd receptors and co-receptor LRP5. MH upregulated the expression levels of both Fzd and LRP5, suggesting Wnt/ $\beta$-catenin signaling activation is sensitive to MH concentration. Most importantly, the transcript level of Fzd was positively correlated with the Wnt transcript expression level. Wnt-mediated Fzd/LRP5 stimulation leads to cytosolic $\beta$-catenin accumulation. However, its accumulation and signaling are tightly regulated via Wnt-dependent and Wnt-independent mechanisms [37]. Evidence shows that $\beta$-catenin signaling is essential for proper vascular formation and the development and functioning of the heart [38]. Next, investigations were performed to measure the expression pattern of $\beta$-catenin mRNA in MH-treated embryos. There was an increase in $\beta$-catenin mRNA. Since $\beta$-catenin has a rapid turnover [37], we explored the expression of GSK3 $\beta$ transcript. Evidence indicates that GSK3 $\beta$ activity is reduced/inactivated in the presence of Wnt signal [37]. As shown in Figure 8, GSK3 $\beta$ expression was unaltered, which is critical to the activation of $\beta$-catenin-mediated signaling. Moreover, our data suggested that $\mathrm{MH}$ had no direct effect on GSK $3 \beta$ gene expression and the unaltered level of GSK3 $\beta$ might be due to overexpression of Wnt levels, its binding to the complex of Fzd-LRP5, and stabilization of $\beta$-catenin [37]. Inactivation of 
GSK3 $\beta$ can result in the translocation of $\beta$-catenin to the nucleus and, subsequently, the induction of $\beta$-catenin-dependent downstream target genes.

Urokinase plasminogen activator receptor (UPAR) [39] is one of these target genes downstream of $\beta$-catenin that has roles in both thrombosis and complement system. tPA and uPA are two plasminogen activators which are capable of catalyzing the activation of plasminogen. While uPA is required for the generation of plasmin activity in tissue undergoing pathological remodeling, tPA is associated with plasmin-induced activation of latent TGF- $\beta$ in the vessel wall [40]. TGF $\beta 2$, a cytokine, is involved in vascular function, and mutations in TGF $\beta 2$ are found to be implicated in cardiovascular diseases such as vascular complications and aortic disease [41]. The activity of uPA is regulated by its specific receptor, uPAR [42]. The mRNA of PAI-1 and uPA were enhanced by MH treatment in medaka embryos, whereas tPA mRNA steady-state levels were unaffected (Figure 5A). Similarly, TGF $\beta 2$ mRNA was unaffected by $\mathrm{MH}$ (Figure 8). This coincides well with the finding in the vascular wall [40] that there is a potential direct correlation between tPA expression and TGF $\beta 2$ gene expression and/or activation. The tPA/PAI-1 mRNA ratio was significantly decreased in the $10 \mu \mathrm{M}$ MH group compared to the control. This suggests that MH appears to influence the fibrinolytic system during embryogenesis. In addition, Dvl mRNA was significantly elevated in MH-treated embryos. Overexpression of Dvl can inhibit the phosphorylation of $\beta$-catenin by GSK3 $\beta$ leading to $\beta$-catenin stabilization, and can consequently promote expression of the downstream targets. Overexpression of Dvl-1 in an atorvastatin-treated rat model of balloon-injured carotid artery has been shown to reverse the treatment effects of atorvastatin on vascular smooth muscle cells and collagen expression [43], suggesting the anti-restenosis action of Dvl. Collectively, these results also confirm that there is a positive correlation between $\beta$-catenin increases and the level of downstream target gene expression.

While DKK-1 is a transcriptional target of the p53 tumor suppressor [44] and $\beta$-catenin [45], it plays a functionally redundant but protective role [46]. It is capable of suppressing the expression of Wnt target genes [47] during postnatal angiogenesis [48]. MH causes an overexpression of the DKK-1 gene in embryos. Our data has demonstrated that both the Wnt/ $\beta$-catenin signaling and its modulator, DKK-1, are increased in MH-treated embryos, highlighting their imbalance pattern of expression. Evidence indicates that the overexpression of DKK-1 is markedly associated with reduced cell proliferation [45], endothelial dysfunction, and concomitant platelet activation [49]. There is a positive correlation between DKK-1 expression and the recovery period following acute myocardial infarction (MI) [50]. FVII, FX, and FXI were elevated in MH-treated embryos, suggesting their consumption due to the activation of platelets. Activation of platelets lead to the formation of thrombus and reduced blood flow, which was apparent in MH-treated embryos. It is well-established that reduced blood supply to the myocardial tissues can result in ischemia and subsequent MI. On the basis of plaque rupture, platelets are found to be the cellular source of DKK-1 in patients with acute ST segment-elevated MI [51]. In addition, our study also demonstrates that $\mathrm{MH}$ is capable of upregulating the gene expression of brain type natriuretic peptide (a secretory cardiac neurohormone, BNP) and Troponin T, which has cardiac specificity and is essential for cardiac contractility [52]. There is a positive correlation between elevated troponin levels and ST-segment elevation MI (STEMI) [52]. Elevated BNP levels are a strong predictive marker of heart failure [53]. It is plausible to suggest that overexpression of the components of the Wnt $1 / \beta$-catenin dependent pathway by $\mathrm{MH}$ is due to heart failure and ischemic areas in the embryo heart during the wound healing process following acute MI, whereas MH-induced increased DKK-1 gene expression is mediated via platelet-induced endothelial activation.

Although this is the first work in the literature to have explored the effects of $\mathrm{MH}$ on inflammatory cytokines in medaka, MH surprisingly caused robust increased levels of inflammatory markers such as TNF- $\alpha$ and IL-1 $\beta$ (Figure 6) in contrast to those of honokiol and magnolol. Our study did not address the differences we observed in the MH-mediated increased inflammatory mediators. We do not have a ready explanation for the discrepancy regarding the cited anti-inflammatory action of $\mathrm{MH}$ and that of our study. However, it is tempting to suggest that the elevation of these cytokines could be the result of at least two potential explanation: (1) elevated inflammatory mediators in medaka 
embryos were the result of genetic differences passed down from parents in our medaka colony or (2) the additive effect of $\mathrm{MH}$ on constitutive expression of the aforementioned cytokines in medaka as previously seen in mouse embryos [54]. The underlying mechanism(s) for the increase in these cytokines in MH-treated embryos remains uncertain. The increases in TNF- $\alpha$ and IL- $1 \beta$ are positively correlated with the presence and extent of cardiac biomarkers level (Figure 5). There is a wealth of knowledge about the association between heart failure and circulating inflammatory cytokines [55]. It is tempting to suggest that MH-induced inflammation might be the result of local tissue injury due to lack of oxygen/nutrients or systemic inflammasome activation. However, further investigation is needed to determine the potential causative role these inflammatory cytokines play in the progression of MH-induced cardiac injury.

\section{Materials and Methods}

\subsection{Medaka Maintenance and Breeding}

All fish work was performed in compliance with animal ethics guidelines as given by the Institutional Animal Care and Use Committee (IACUC) at the University of Mississippi according to the Association for Assessment and Accreditation of Laboratory Animal Care International (AAALAC). Embryos were collected in the morning and maintained on a $14 \mathrm{~h}: 10 \mathrm{~h}$ light:dark cycle. The medium or test solutions as well as plates were autoclaved or sterilized. All experiments with medaka embryos were conducted in an embryo medium $\left(17 \mathrm{mM} \mathrm{NaCl}, 0.4 \mathrm{mM} \mathrm{KCl}, 0.36 \mathrm{mM} \mathrm{CaCl}_{2}, 0.6 \mathrm{mM} \mathrm{MgSO}_{4}\right.$, $\mathrm{pH} 7.4$, and $0.0002 \%$ methylene blue) at $26 \pm 1{ }^{\circ} \mathrm{C}$.

Natural breeding or in vitro fertilization (known as squeezing) was used as a preferred method of choice for generating embryos for pharmacological treatment experiments. The latter techniques were used to generate embryos for most of our experiments, unless otherwise stated.

\subsection{Extraction and Isolation of $M H$}

The seeds of Magnolia grandiflora were collected at the University of Mississippi campus (MS 38677). Air-dried powdered seeds ( $107 \mathrm{~g})$ were soaked in $\mathrm{EtOH}(200 \mathrm{~mL} \times 2 \times 24 \mathrm{~h}$ each). The combined extract afforded oily material, where $2 \mathrm{~g}$ was subjected to centrifugal preparative thin layer chromatography (CPTLC, Chromatotron ${ }^{\circledR}$, Analtech Inc., Newark, DE, USA), using a $6 \mathrm{~mm}$ silica gel rotor. The sample was dissolved in dichloromethane (DCM) and applied to the rotor under a rotation of $700 \mathrm{rpm}$, and subsequently eluted with $n$-hexane, then DCM, to end up with $\mathrm{MeOH}$ (200 $\mathrm{mL}$ each). Eighteen fractions were monitored and collected via TLC analysis (silica gel; solvents: $n$-hexane-EtOAc; 75:25). The fractions were visualized by spraying the TLC plates, with $1 \%$ vanillin- $\mathrm{H}_{2} \mathrm{SO}_{4}$ used as a spray reagent, where fractions $6(361 \mathrm{mg})$ and $7(36.0 \mathrm{mg})$ contained $\mathrm{MH}$ with a purity of $95 \%$ and $85 \%$, respectively, via LC and NMR analyses. Further purification of fraction 6 was completed using a silica gel solid phase extraction cartridge (SPE) and was eluted with gradient of $n$-hexane/EtOAc $(100: 0 \rightarrow 99: 1)$ with $0.1 \%$ increments to afford 10 fractions. The fractions were monitored and pooled by TLC analysis (silica gel; solvents: n-Hex-EtOAc; 75:25), where fractions 7-9 afforded MH with a purity of $95 \%$ via LC and NMR analyses. LC analysis was conducted using an Agilent 1100 high performance liquid chromatography (HPLC) system equipped with a degasser (G1379A), quaternary pump (G13311A), auto sampler (G1313A), column oven (G1316A), and UV-Diode detector (G1315B) controlled by Chemstation software. Analysis of the fractions was carried out on an RP-C18 column $\left(150 \times 4.6 \mathrm{~mm}\right.$; particle size $5 \mu \mathrm{m}$; Luna) with column oven temperature set to $25^{\circ} \mathrm{C}$ and a gradient system of eluent water (A) and acetonitrile (B) used. The gradient condition was as follows: $0-2 \mathrm{~min}$ $(10 \% \mathrm{~B}), 2-30 \mathrm{~min}(10 \% \mathrm{~B} \rightarrow 90 \% \mathrm{~B}), 30-35 \mathrm{~min}(100 \% \mathrm{~B})$. The flow rate of the solvent was $1.0 \mathrm{~mL} / \mathrm{min}$ and the injection volume was $20 \mu \mathrm{L}$. All the analysis was carried out at wavelengths of 254, 280, and $325 \mathrm{~nm}$ with a run time of $35 \mathrm{~min}$. HPLC-grade acetonitrile and water solvents were used. Acetic acid was added as a modifier to achieve a final concentration of $0.1 \%$ in each solvent. NMR spectra were acquired on a Varian Mercury $400 \mathrm{MHz}$ spectrometer at $400\left({ }^{1} \mathrm{H}\right)$ and $100\left({ }^{13} \mathrm{C}\right) \mathrm{MHz}$ in $\mathrm{CDCl}_{3}$, 
using the residual solvent as an internal standard. Multiplicity determinations (DEPT) and 2D-NMR spectra (HMQC, HMBC, and NOESY) were obtained using standard Bruker pulse programs.

\section{3. $M H$ Treatment}

The up-and-down procedure (UDP) testing approach was used to determine the toxicity of MH on medaka, beginning at stage 9 (hour 5) of embryological development (as delineated by [56,57]) (Figure 10). For the analysis of the effects of pharmacological treatments on cardiac rate, thrombus generation, and blood vessel occlusion, fertilized eggs were collected within $5 \mathrm{~h}$ of mating and immersed in embryo medium containing various concentrations of $\mathrm{MH}(1,2,5,10$, and $20 \mu \mathrm{M})$ and $0.02-0.04 \%$ DMSO (control group) in 48-well culture plates. The first batch of embryos (0-6 dpf, $n=8$ to 12 embryos/group) was exposed to five different concentrations $(1,2,5,10$, and $20 \mu \mathrm{M})$ of $\mathrm{MH}$ and vehicle sample, $0.02-0.04 \%$ DMSO, which is known to be safe [58] and increase the permeability [59] of the embryo's chorion. The second batch of embryos (2-6 dpf) was exposed to similar dilutions of MH $(1,2,5,10$, and $20 \mu \mathrm{M})$ and $0.02-0.04 \%$ DMSO. All embryos were placed in a 48-well plate with $1 \mathrm{~mL}$ of their respective dilutions. Both batches were monitored for changes in morphology, delayed growth, behavior alteration, and mortality throughout the embryonic and larval-, juvenile-, and adult-life stages.

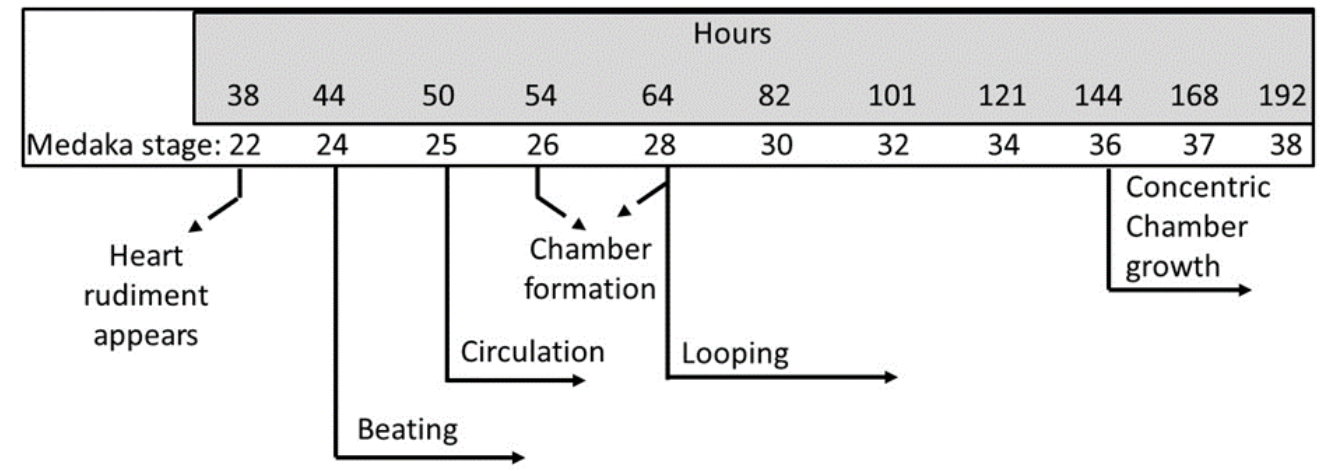

Figure 10. Stages with regard to hours post fertilization of the medaka heart. This scheme outlines the embryological development of the heart during the first $144 \mathrm{~h}$ and subsequent formation of concentric chamber growth. The medaka heart begins beating and pumping around 44 (stage 24) to 50 (stage 25) hours post fertilization. Medaka embryos were treated with $\mathrm{MH}$ either from $0-6$ days post fertilization or $2-6 \mathrm{dpf}$ at $26 \pm 1{ }^{\circ} \mathrm{C}$.

Embryos and larvae were raised in 48-well plates and maintained at a density of $1 / 1.0 \mathrm{~mL}$ in embryo medium with daily medium change. Groups of medaka embryos, often numbering 8 to 12 , were exposed for an exposure period from 0 to 6 days post fertilization (organogenesis period at stages 9 to 36-38), and 2 to $6 \mathrm{dpf}$ (stages 25 to 36-38), with an interval of at least $24 \mathrm{~h}$. Embryos/hatched fry were reared in normal embryo medium at 6-10 dpf without MH (washed groups). Survivability, hatching efficiency, blood vessel occlusion, and blood flow frequency were observed until $10 \mathrm{dpf}$. Heart beats were counted on 3 and $6 \mathrm{dpf}$, and RNA isolation was immediately performed after 0-6 dpf exposure. Behavioral experiments were conducted two days post hatching (dph) after 0-6 dpf MH exposure. Larvae with no obvious malformation were used for locomotion experiments. Both embryos and larvae were monitored daily by imaging.

\subsection{Determination of MH Purity and MH Absorption in Medaka Embryos}

The absorption of $\mathrm{MH}$ from embryo medium to embryos were ascertained after a single concentration of $\mathrm{MH}(10 \mu \mathrm{M})$ for a period of $24 \mathrm{~h}$ using an Agilent 1290 Infinity series UHPLC with a diode array detector and an Agilent 6120 quadrupole mass spectrometer (Agilent Technologies, Santa Clara, CA, USA). The highly purified MH reference standard showed a base peak of $[\mathrm{M}+\mathrm{H}]^{+}$ 
281 with the APCI positive ionization mode; this ion was thus used in a selected ion monitoring mode (SIM) to detect $\mathrm{MH}$ in the samples. Embryos were exposed to embryo medium containing $10 \mu \mathrm{M}$ $\mathrm{MH}$ from $5 \mathrm{~h}$ post fertilization (hpf) to $24 \mathrm{hpf}$. The disappearance of $\mathrm{MH}$ in the embryo's bathing (conditioned) medium was regarded as the absorption characterization of $\mathrm{MH}$ in the embryo toxicity test and the cardiovascular toxicity test. The identity and concentration of $\mathrm{MH}$ in conditioned medium was measured by UHPLC/MS.

The toxicity testing involved multi-stage exposure with repeated $\mathrm{MH}$ concentrations for six consecutive days with an interval of at least $24 \mathrm{~h}$. Six groups of embryos ( $n=12$ /group) were treated concurrently with 1, 2, 5, 10, and $20 \mu \mathrm{M} \mathrm{MH}$ and 0.02-0.04\% DMSO (control group) at $5 \mathrm{hpf}$. There was a washout period between each treatment to clear any remaining free $\mathrm{MH}$ and extruded molecules into the conditioned embryo medium. The stock solution of $\mathrm{MH}$ was prepared in $100 \%$ DMSO (Sigma-Aldrich, St. Louis, MO, USA). Treatment was done according to the design depicted in Figure 10. In another set of experiments, hatched fry were reared in normal embryo medium without MH until $10 \mathrm{dpf}$ (washed groups).

\subsection{Microscopy Study}

Control and treated fish were sampled at various stages of development according to the treatment schedule. Cardiovascular structure, blood flow, and heartbeat were analyzed under a microscope. Images were acquired on a Nikon TI2-E inverted microscope with a white light LED illuminator and a sCMOS Cooled Monochrome Camera. Videos were captured using Nikon Elements automated acquisition at a rate of 20 frames per second for one minute.

\subsection{Locomotion Study}

The free-swimming behavior of MH-treated larvae was compared to that of the control group. $\mathrm{MH}$ was prepared at a $5 \mu \mathrm{M}$ concentration in embryo medium. This concentration was selected on the basis of $\mathrm{LC}_{50}$ studies. The effects of acute $\mathrm{MH}$ exposure on locomotor activity in larvae were examined at $2 \mathrm{dph}$. We assessed activity in 24-well plates. Larvae were placed individually in wells containing $2 \mathrm{~mL}$ of embryo medium. The larvae acclimatized to the darkness of the Zebrabox over $20 \mathrm{~min}$ (Viewpoint, Montreal, Canada) before the start of the locomotion experiment. The duration of movements was measured at a velocity of $\geq 2 \mathrm{~mm} / \mathrm{s}$.

\subsection{RNA Extraction}

The isolated heart of the medaka embryo from the $6 \mathrm{dpf}$ control and MH-treated embryos was too small to obtain from it enough total RNA for the quantification of target genes. To overcome this problem, 100 embryos from the $6 \mathrm{dpf}$ control and MH-treated embryos were pooled into one sample and RNA was extracted using an RNAeasy micro kit (QIAGEN GmbH) following the manufacturer's protocol. However, samples were replicated four times.

\subsection{Reverse Transcription-Quantitative Polymerase Chain Reaction (RT-qPCR)}

One microgram of total RNA extracted from each sample were reverse-transcribed into cDNA using a Quantitect RT kit (QIAGEN GmbH). Quantitative expression profiles of the genes of interest were analyzed using SYBR Green (Invitrogen, Carlsbad, CA, USA) according to the instructions of the manufacturer. Primers used for the amplification of each gene have been tabulated in Table 1. 
Table 1. Oligonucleotide sequences used in this study.

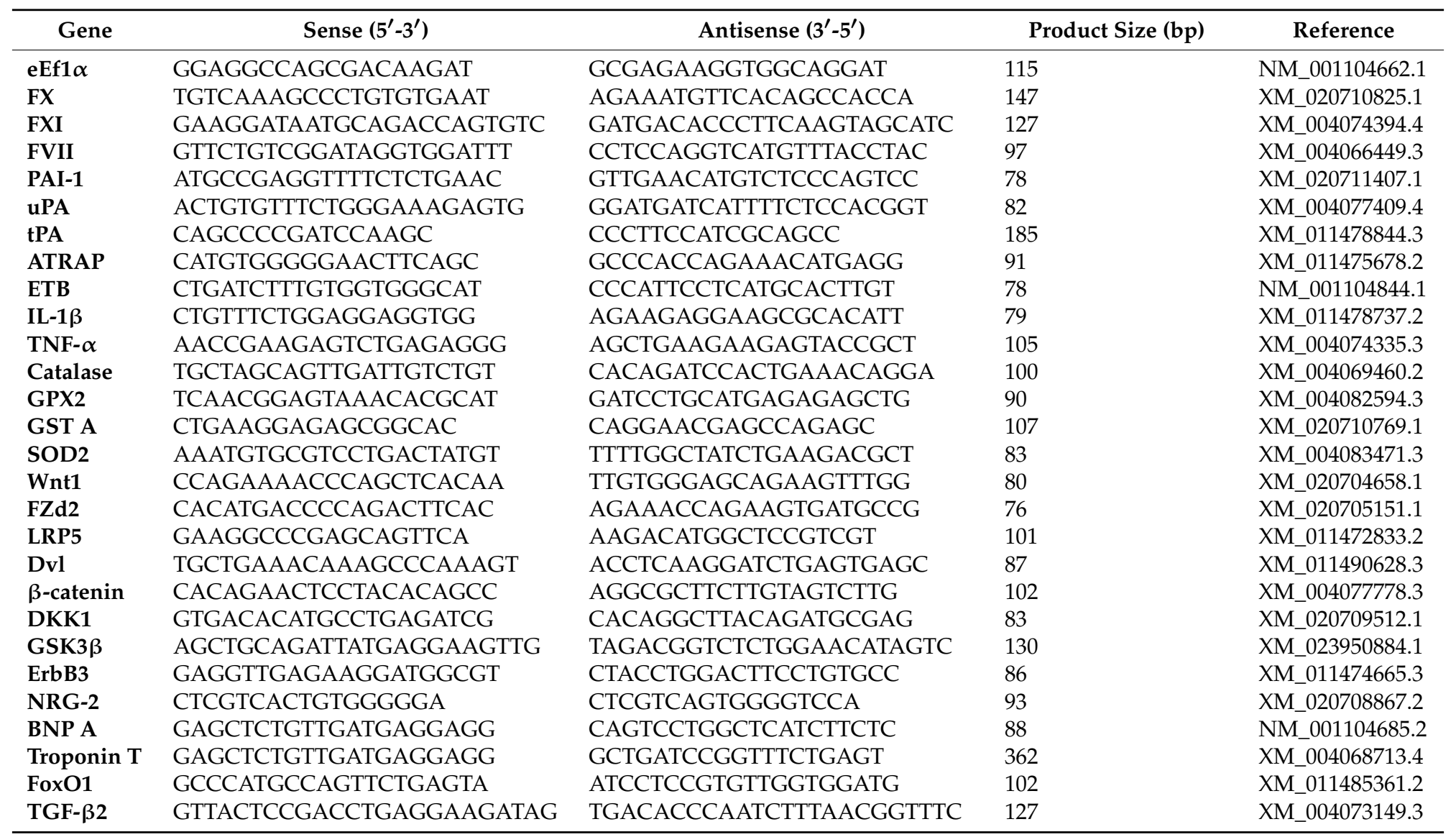


Quantification of target genes were done using an ABI 7000 real-time PCR machine (Applied Biosystems, Inc., Foster City, CA, USA). To measure the relative quantity of target genes per $1 \mu \mathrm{g}$ of the total RNA from each group, a $2^{-\Delta \Delta C t}$ method was used. On the basis of McCurley and Callard's 2008 study [60] as well as our own observations, eEf1 $\alpha$ was included as an internal control. Samples were replicated four times. Quantitative expression data were used as the basis for making the major interpretations of this study.

\subsection{Statistical Analyses}

Statistical analysis was performed using Graph Pad Prism V6.0. Data are presented as mean \pm SEM. Morphological data were analyzed by one-way ANOVA followed by Tukey's post-hoc multiple comparison test where more than two groups were compared. The $\mathrm{LC}_{50}$ was calculated by $\log$ transformed data using nonlinear regression (curve-fit) (GraphPad Prism). Statistical analysis for all RT-qPCR data was performed by two-way ANOVA followed by post-hoc Bonferroni test. Data for locomotion study were analyzed by two-tailed $t$-test. A difference between two means was considered to be significant when $p<0.05\left({ }^{*} p<0.05\right)$.

\section{Conclusions}

Natural product extracts play complex roles in cardiovascular homeostasis. They can have protective and exacerbating effects on diseases due to the presence and complexity of plant extract composition. There has been very little information produced about the pharmacodynamics and pharmacokinetics [61] of MH, particularly in regard to both its teratogenic and cardiovascular effects. The typical recommended levels of magnolia bark extracts range from 200-800 mg/day/person [62]. The potential effects of $\mathrm{MH}$ on embryonic development are prominently apparent in our current study (Figure 11). Since medaka can be used to model the human cardiovascular system [57], here we report that $\mathrm{MH}$ alone is harmful to embryos because of its proinflammatory and prothrombotic properties as well as its effects on the Wnt signaling pathway. Unfortunately, little is known about the contribution(s) of $\mathrm{MH}$ once the trajectory has been set following its ingestion in humans. Our evidence is not sufficiently robust to support and extrapolate its deleterious effects in humans. However, we suggest that its inclusion in plant extracts could potentially retard the beneficial effects of other components of magnolia bark extracts or others. Herbal medicine optimization research must take $\mathrm{MH}$ levels into consideration in order to prevent the stimulation of both stress-induced pathways and the Wnt signaling pathway, which plays major roles in the control of all facets of embryonic development. Complementary approaches are needed to have a better understanding of the effects of maternal use of plant extracts containing MH on the offspring's health during pregnancy. 
The potential causal effect of $\mathrm{MH}$ on medaka embryos

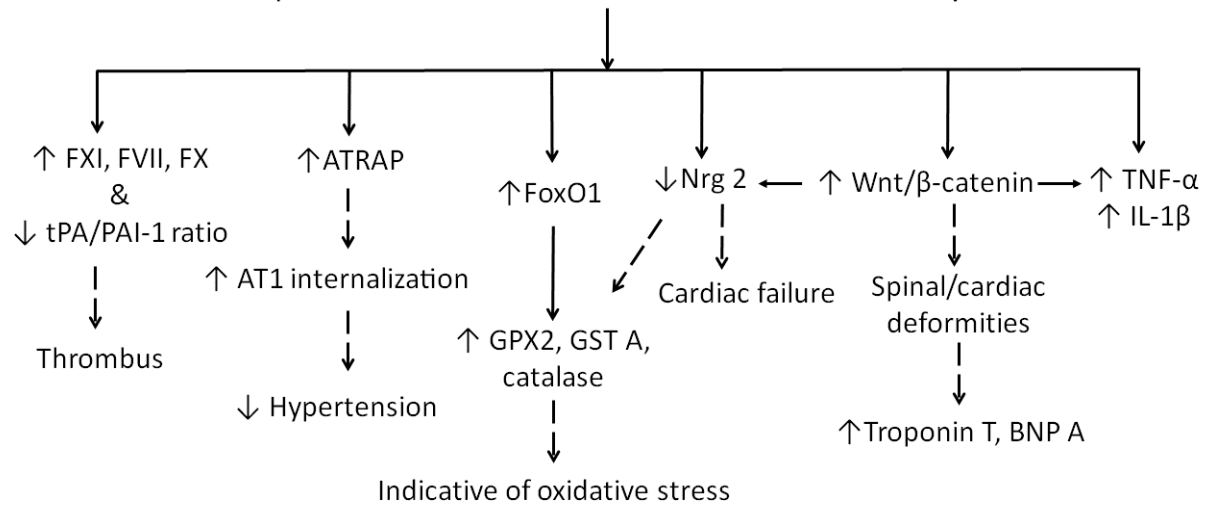

Figure 11. Flowchart depicting $\mathrm{MH}$ treatment induces cellular and morphological changes in medaka embryos that lead to inflammation, thrombosis, spinal, and cardiac deformities. Solid arrows indicate the direction of the effects of $\mathrm{MH}$ on indicators of increased inflammation/cardiovascular risk and the anatomic locations as well as a link with the prior object/event. The flow of physiological changes that require further investigations are shown in dashed arrows. Legend: ATRAP, angiotensin receptor-associated protein; AT1, angiotensin type I receptor; $\beta$-catenin, beta catenin; BNPA, brain natriuretic peptide type A; FVII, Factor VII; FX, Factor X; FXI, Factor XI; FoxO1, Forkhead box O1; GPX2, glutathione peroxidase 2; GST A, glutathione S-transferase A; IL-1 $\beta$, interleukin-1 beta; Nrg 2, neuregulin 2; tPA, urokinase plasminogen activator; PAI-1, plasminogen activator inhibitor 1 ; Wnt, wingless/integrated oncogenes.

Supplementary Materials: The following are available online.

Author Contributions: Conceptualization, Z.S.-M.; Data curation, S.K.S.; Funding acquisition, Z.S.-M.; Investigation, S.K.S. and M.W.; Methodology, M.A.I.; Resources, I.M. and Z.S.-M.; Validation, I.M., M.A.I., M.W., and Z.S.-M.; Visualization, N.M.A.; Writing—original draft, Z.S.-M.; Writing—review \& editing, S.K.S., I.M., M.A.I., M.W., N.M.A., and Z.S.-M.

Funding: This work was supported by the University of Mississippi overhead account to ZSM and partially supported by the United State Department of Agriculture, Agricultural Research Service (USDA ARS) Specific Cooperative Agreement No. 58-6408-2-00.

Acknowledgments: The authors thank Yan-Hong Wang (University of Mississippi, USA) for the assistance with HPLC. The authors also thank A.K. Dasmahapatra (Jackson State University, Mississippi, USA) for his challenging advice and comments. Part of the data from this article were presented at the Society of Toxicology Annual Meeting, San Antonio Meeting, 11-15 March 2018.

Conflicts of Interest: The authors declare no competing interests. The contents of this article are the sole responsibility of the authors and do not necessarily represent the official University of Mississippi or the grant agency officials.

\section{Abbreviations}

$\begin{array}{ll}\text { ATRAP } & \text { AT II type 1 receptor-associated protein } \\ \text { BNP A } & \text { Brain natriuretic peptide A } \\ \text { CAT } & \text { Catalase } \\ \text { DKK1 } & \text { Dickkopf } 1 \\ \text { dpf } & \text { Days post fertilization } \\ \text { dph } & \text { Days post hatching } \\ \text { Dvl } & \text { Dishevelled } \\ \text { eEf1 } \alpha & \text { Eukaryotic elongation factor 1 alpha } \\ \text { ErbB } & \text { Erythroblastic leukemia viral oncogene homolog } \\ \text { ET } & \text { Endothelin receptor B } \\ \text { FoxO1 } & \text { Forkhead box O1 } \\ \text { Fzd } & \text { Frizzled } \\ \text { GPX 2 } & \text { Glutathione peroxidase 2 } \\ \text { GSK-3 } \beta & \text { Glycogen synthase kinase } 3 \text { beta }\end{array}$




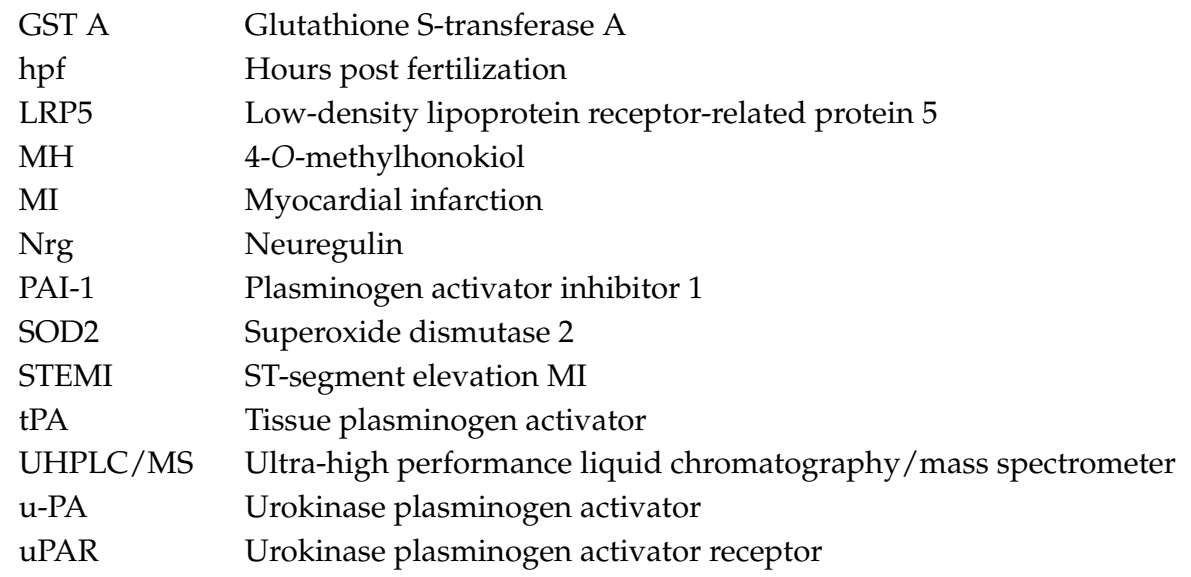

\section{Appendix A}

Figure A1 shows the images representing the medaka phenotype following MH treatment.

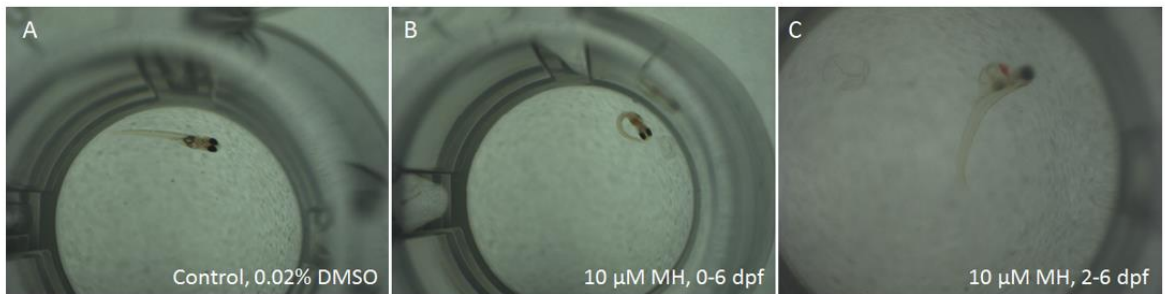

Figure A1. Examples of images representing the medaka phenotype following MH treatment. Medaka embryos were treated with $10 \mu \mathrm{M}$ MH or an untreated control batch (0.02\% DMSO) for 0-6 dpf or 2-6 dpf following the same protocol as described in the method. (A) Control. No phenotypic abnormality was detected with the control for the two groups. This first image displays an example of a typical control obtained immediately for both treatment plans. (B) This is an example of a typical medaka treated with $10 \mu \mathrm{M}$ MH for 0-6 dpf. Curved tail phenotypes were observed in many. (C) Edema phenotypes were observed in medaka treated with $10 \mu \mathrm{M}$ MH for 2-6 dpf. Bent tail phenotypes were observed in few.

\section{Appendix B}

The effect of MH on heart function. These videos show how the medaka heart functions normally (Video 1) and when it is exposed to $10 \mu \mathrm{M} \mathrm{MH}$ for six days of treatment from $5 \mathrm{~h}$.

\section{References}

1. Li, N.; Song, Y.; Zhang, W.; Wang, W.; Chen, J.; Wong, A.W.; Roberts, A. Evaluation of the in vitro and in vivo genotoxicity of magnolia bark extract. Regul. Toxicol. Pharmacol. 2007, 49, 154-159. [CrossRef]

2. Shen, J.L.; Man, K.M.; Huang, P.H.; Chen, W.C.; Chen, D.C.; Cheng, Y.W.; Liu, P.L.; Chou, M.C.; Chen, Y.H. Honokiol and magnolol as multifunctional antioxidative molecules for dermatologic disorders. Molecules 2010, 15, 6452-6465. [CrossRef] [PubMed]

3. Chicca, A.; Gachet, M.S.; Petrucci, V.; Schuehly, W.; Charles, R.P.; Gertsch, J. 4'-O-methylhonokiol increases levels of 2-arachidonoyl glycerol in mouse brain via selective inhibition of its COX-2-mediated oxygenation. J. Neuroinflamm. 2015, 12, 89. [CrossRef] [PubMed]

4. Dominguez, F.; Chavez, M.; Garduno-Ramirez, M.L.; Chavez-Avila, V.M.; Mata, M.; Cruz-Sosa, F. Honokiol and magnolol production by in vitro micropropagated plants of Magnolia dealbata, an endangered endemic Mexican species. Nat. Prod. Commun. 2010, 5, 235-240. [PubMed]

5. Schuhly, W.; Khan, S.I.; Fischer, N.H. Neolignans from North American Magnolia species with cyclooxygenase 2 inhibitory activity. Inflammopharmacology 2009, 17, 106-110. [CrossRef] [PubMed]

6. Bernaskova, M.; Schoeffmann, A.; Schuehly, W.; Hufner, A.; Baburin, I.; Hering, S. Nitrogenated honokiol derivatives allosterically modulate GABAA receptors and act as strong partial agonists. Bioorg. Med. Chem. 2015, 23, 6757-6762. [CrossRef] 
7. Lin, C.F.; Hwang, T.L.; Al-Suwayeh, S.A.; Huang, Y.L.; Hung, Y.Y.; Fang, J.Y. Maximizing dermal targeting and minimizing transdermal penetration by magnolol/honokiol methoxylation. Int. J. Pharm. 2013, 445, 153-162. [CrossRef]

8. Fang, J.Y.; Huang, T.H.; Hung, C.F.; Huang, Y.L.; Aljuffali, I.A.; Liao, W.C.; Lin, C.F. Derivatization of honokiol by integrated acetylation and methylation for improved cutaneous delivery and anti-inflammatory potency. Eur. J. Pharm. Sci. 2018, 114, 189-198. [CrossRef]

9. Kim, H.S.; Ryu, H.S.; Kim, J.S.; Kim, Y.G.; Lee, H.K.; Jung, J.K.; Kwak, Y.S.; Lee, K.; Seo, S.Y.; Yun, J.; et al. Validation of cyclooxygenase-2 as a direct anti-inflammatory target of 4-O-methylhonokiol in zymosan-induced animal models. Arch. Pharm. Res. 2015, 38, 813-825. [CrossRef]

10. Chiu, J.H.; Ho, C.T.; Wei, Y.H.; Lui, W.Y.; Hong, C.Y. In vitro and in vivo protective effect of honokiol on rat liver from peroxidative injury. Life Sci. 1997, 61, 1961-1971. [CrossRef]

11. Huang, L.; Zhang, K.; Guo, Y.; Huang, F.; Yang, K.; Chen, L.; Huang, K.; Zhang, F.; Long, Q.; Yang, Q. Honokiol protects against doxorubicin cardiotoxicity via improving mitochondrial function in mouse hearts. Sci. Rep. 2017, 7, 11989. [CrossRef] [PubMed]

12. Lee, Y.J.; Choi, D.Y.; Lee, Y.K.; Lee, Y.M.; Han, S.B.; Kim, Y.H.; Kim, K.H.; Nam, S.Y.; Lee, B.J.; Kang, J.K.; et al. 4-O-methylhonokiol prevents memory impairment in the Tg2576 transgenic mice model of Alzheimer's disease via regulation of beta-secretase activity. J. Alzheimer's Dis. 2012, 29, 677-690. [CrossRef] [PubMed]

13. Bunel, V.; Antoine, M.H.; Stevigny, C.; Nortier, J.; Duez, P. New in vitro insights on a cell death pathway induced by magnolol and honokiol in aristolochic acid tubulotoxicity. Food Chem. Toxicol. 2016, 87, 77-87. [CrossRef] [PubMed]

14. Greenberg, M.; Urnezis, P.; Tian, M. Compressed mints and chewing gum containing magnolia bark extract are effective against bacteria responsible for oral malodor. J. Agric. Food Chem. 2007, 55, 9465-9469. [CrossRef] [PubMed]

15. Hsu, H.T.; Chi, C.W. Emerging role of the peroxisome proliferator-activated receptor-gamma in hepatocellular carcinoma. J. Hepatocell. Carcinoma 2014, 1, 127-135. [PubMed]

16. Rijken, D.C.; Hoylaerts, M.; Collen, D. Fibrinolytic properties of one-chain and two-chain human extrinsic (tissue-type) plasminogen activator. J. Biol. Chem. 1982, 257, 2920-2925. [PubMed]

17. Kobayashi, R.; Wakui, H.; Azushima, K.; Uneda, K.; Haku, S.; Ohki, K.; Haruhara, K.; Kinguchi, S.; Matsuda, M.; Ohsawa, M.; et al. An angiotensin II type 1 receptor binding molecule has a critical role in hypertension in a chronic kidney disease model. Kidney Int. 2017, 91, 1115-1125. [CrossRef]

18. Wakui, H.; Dejima, T.; Tamura, K.; Uneda, K.; Azuma, K.; Maeda, A.; Ohsawa, M.; Kanaoka, T.; Azushima, K.; Kobayashi, R.; et al. Activation of angiotensin II type 1 receptor-associated protein exerts an inhibitory effect on vascular hypertrophy and oxidative stress in angiotensin II-mediated hypertension. Cardiovasc. Res. 2013, 100, 511-519. [CrossRef]

19. Ford, B.D.; Liu, Y.; Mann, M.A.; Krauss, R.; Phillips, K.; Gan, L.; Fischbach, G.D. Neuregulin-1 suppresses muscarinic receptor expression and acetylcholine-activated muscarinic $\mathrm{K}+$ channels in cardiac myocytes. Biochem. Biophys. Res. Commun. 2003, 308, 23-28. [CrossRef]

20. Petrie, T.A.; Strand, N.S.; Yang, C.T.; Rabinowitz, J.S.; Moon, R.T. Macrophages modulate adult zebrafish tail fin regeneration. Development 2014, 141, 2581-2591. [CrossRef]

21. Potente, M.; Urbich, C.; Sasaki, K.; Hofmann, W.K.; Heeschen, C.; Aicher, A.; Kollipara, R.; DePinho, R.A.; Zeiher, A.M.; Dimmeler, S. Involvement of Foxo transcription factors in angiogenesis and postnatal neovascularization. J. Clin. Investig. 2005, 115, 2382-2392. [CrossRef] [PubMed]

22. Hagenmaier, H.E. The hatching process in fish embryos. IV. The enzymological properties of a highly purified enzyme (chorionase) from the hatching fluid of the rainbow trout, Salmo gairdneri Rich. Comp. Biochem. Physiol. Part B Comp. Biochem. 1974, 49, 313-324. [CrossRef]

23. Buikema, J.W.; Mady, A.S.; Mittal, N.V.; Atmanli, A.; Caron, L.; Doevendans, P.A.; Sluijter, J.P.; Domian, I.J. Wnt/beta-catenin signaling directs the regional expansion of first and second heart field-derived ventricular cardiomyocytes. Development 2013, 140, 4165-4176. [CrossRef]

24. Bajoghli, B.; Aghaallaei, N.; Jung, G.; Czerny, T. Induction of otic structures by canonical Wnt signalling in medaka. Dev. Genes Evol. 2009, 219, 391-398. [CrossRef] [PubMed]

25. Loh, N.Y.; Neville, M.J.; Marinou, K.; Hardcastle, S.A.; Fielding, B.A.; Duncan, E.L.; McCarthy, M.I.; Tobias, J.H.; Gregson, C.L.; Karpe, F.; et al. LRP5 regulates human body fat distribution by modulating adipose progenitor biology in a dose- and depot-specific fashion. Cell Metab. 2015, 21, 262-273. [CrossRef] [PubMed] 
26. Ackers, I.; Malgor, R. Interrelationship of canonical and non-canonical Wnt signalling pathways in chronic metabolic diseases. Diabetes Vasc. Dis. Res. 2018, 15, 3-13. [CrossRef]

27. Nguyen, G. Renin, (pro)renin and receptor: An update. Clin. Sci. 2011, 120, 169-178. [CrossRef]

28. Bisson, J.A.; Mills, B.; Paul Helt, J.C.; Zwaka, T.P.; Cohen, E.D. Wnt5a and Wnt11 inhibit the canonical Wnt pathway and promote cardiac progenitor development via the Caspase-dependent degradation of AKT. Dev. Biol. 2015, 398, 80-96. [CrossRef] [PubMed]

29. Ueno, S.; Weidinger, G.; Osugi, T.; Kohn, A.D.; Golob, J.L.; Pabon, L.; Reinecke, H.; Moon, R.T.; Murry, C.E. Biphasic role for Wnt/beta-catenin signaling in cardiac specification in zebrafish and embryonic stem cells. Proc. Natl. Acad. Sci. USA 2007, 104, 9685-9690. [CrossRef]

30. Sklepkiewicz, P.; Shiomi, T.; Kaur, R.; Sun, J.; Kwon, S.; Mercer, B.; Bodine, P.; Schermuly, R.T.; George, I.; Schulze, P.C.; et al. Loss of secreted frizzled-related protein-1 leads to deterioration of cardiac function in mice and plays a role in human cardiomyopathy. Circ. Heart Fail. 2015, 8, 362-372. [CrossRef]

31. Foulquier, S.; Daskalopoulos, E.P.; Lluri, G.; Hermans, K.C.M.; Deb, A.; Blankesteijn, W.M. WNT Signaling in Cardiac and Vascular Disease. Pharmacol. Rev. 2018, 70, 68-141. [CrossRef] [PubMed]

32. Askevold, E.T.; Aukrust, P.; Nymo, S.H.; Lunde, I.G.; Kaasboll, O.J.; Aakhus, S.; Florholmen, G.; Ohm, I.K.; Strand, M.E.; Attramadal, H.; et al. The cardiokine secreted Frizzled-related protein 3, a modulator of Wnt signalling, in clinical and experimental heart failure. J. Intern. Med. 2014, 275, 621-630. [CrossRef]

33. Barandon, L.; Casassus, F.; Leroux, L.; Moreau, C.; Allieres, C.; Lamaziere, J.M.; Dufourcq, P.; Couffinhal, T.; Duplaa, C. Secreted frizzled-related protein-1 improves postinfarction scar formation through a modulation of inflammatory response. Arterioscler. Thromb. Vasc. Biol. 2011, 31, e80-e87. [CrossRef] [PubMed]

34. Halleskog, C.; Dijksterhuis, J.P.; Kilander, M.B.; Becerril-Ortega, J.; Villaescusa, J.C.; Lindgren, E.; Arenas, E.; Schulte, G. Heterotrimeric G protein-dependent WNT-5A signaling to ERK1/2 mediates distinct aspects of microglia proinflammatory transformation. J. Neuroinflamm. 2012, 9, 111. [CrossRef]

35. Kasaai, B.; Moffatt, P.; Al-Salmi, L.; Lauzier, D.; Lessard, L.; Hamdy, R.C. Spatial and temporal localization of WNT signaling proteins in a mouse model of distraction osteogenesis. J. Histochem. Cytochem. 2012, 60, 219-228. [CrossRef]

36. Tortelote, G.G.; Reis, R.R.; de Almeida Mendes, F.; Abreu, J.G. Complexity of the Wnt/betacatenin pathway: Searching for an activation model. Cell Signal. 2017, 40, 30-43. [CrossRef] [PubMed]

37. Luu, H.H.; Zhang, R.; Haydon, R.C.; Rayburn, E.; Kang, Q.; Si, W.; Park, J.K.; Wang, H.; Peng, Y.; Jiang, W.; et al. Wnt/beta-catenin signaling pathway as a novel cancer drug target. Curr. Cancer Drug Targets 2004, 4, 653-671. [CrossRef]

38. Dawson, K.; Aflaki, M.; Nattel, S. Role of the Wnt-Frizzled system in cardiac pathophysiology: A rapidly developing, poorly understood area with enormous potential. J. Physiol. 2013, 591, 1409-1432. [CrossRef]

39. Koch, A.; Waha, A.; Hartmann, W.; Hrychyk, A.; Schuller, U.; Wharton, K.A., Jr.; Fuchs, S.Y.; von Schweinitz, D.; Pietsch, T. Elevated expression of Wnt antagonists is a common event in hepatoblastomas. Clin. Cancer Res. 2005, 11, 4295-4304. [CrossRef]

40. Grainger, D.J.; Kemp, P.R.; Liu, A.C.; Lawn, R.M.; Metcalfe, J.C. Activation of transforming growth factor-beta is inhibited in transgenic apolipoprotein(a) mice. Nature 1994, 370, 460-462. [CrossRef]

41. Drera, B.; Ritelli, M.; Zoppi, N.; Wischmeijer, A.; Gnoli, M.; Fattori, R.; Calzavara-Pinton, P.G.; Barlati, S.; Colombi, M. Loeys-Dietz syndrome type I and type II: Clinical findings and novel mutations in two Italian patients. Orphanet J. Rare Dis. 2009, 4, 24. [CrossRef] [PubMed]

42. Senthilkumar, K.; Arunkumar, R.; Elumalai, P.; Sharmila, G.; Gunadharini, D.N.; Banudevi, S.; Krishnamoorthy, G.; Benson, C.S.; Arunakaran, J. Quercetin inhibits invasion, migration and signalling molecules involved in cell survival and proliferation of prostate cancer cell line (PC-3). Cell Biochem. Funct. 2011, 29, 87-95. [CrossRef] [PubMed]

43. Hua, J.; Xu, Y.; He, Y.; Jiang, X.; Ye, W.; Pan, Z. Wnt4/beta-catenin signaling pathway modulates balloon-injured carotid artery restenosis via disheveled-1. Int. J. Clin. Exp. Pathol. 2014, 7, 8421-8431.

44. Shou, J.; Ali-Osman, F.; Multani, A.S.; Pathak, S.; Fedi, P.; Srivenugopal, K.S. Human Dkk-1, a gene encoding a Wnt antagonist, responds to DNA damage and its overexpression sensitizes brain tumor cells to apoptosis following alkylation damage of DNA. Oncogene 2002, 21, 878-889. [CrossRef] [PubMed]

45. Li, J.; Gong, W.; Li, X.; Wan, R.; Mo, F.; Zhang, Z.; Huang, P.; Hu, Z.; Lai, Z.; Lu, X.; et al. Recent Progress of Wnt Pathway Inhibitor Dickkopf-1 in Liver Cancer. J. Nanosci. Nanotechnol. 2018, 18, 5192-5206. [CrossRef] [PubMed] 
46. Combes, A.N.; Bowles, J.; Feng, C.W.; Chiu, H.S.; Khoo, P.L.; Jackson, A.; Little, M.H.; Tam, P.P.; Koopman, P. Expression and functional analysis of Dkk1 during early gonadal development. Sex. Dev. 2011, 5, 124-130. [CrossRef]

47. Foley, A.C.; Mercola, M. Heart induction by Wnt antagonists depends on the homeodomain transcription factor Hex. Genes Dev. 2005, 19, 387-396. [CrossRef]

48. Peghaire, C.; Bats, M.L.; Sewduth, R.; Jeanningros, S.; Jaspard, B.; Couffinhal, T.; Duplaa, C.; Dufourcq, P. Fzd7 (Frizzled-7) Expressed by Endothelial Cells Controls Blood Vessel Formation Through Wnt/beta-Catenin Canonical Signaling. Arterioscler. Thromb. Vasc. Biol. 2016, 36, 2369-2380. [CrossRef]

49. Lattanzio, S.; Santilli, F.; Liani, R.; Vazzana, N.; Ueland, T.; Di Fulvio, P.; Formoso, G.; Consoli, A.; Aukrust, P.; Davi, G. Circulating dickkopf-1 in diabetes mellitus: Association with platelet activation and effects of improved metabolic control and low-dose aspirin. J. Am. Heart Assoc. 2014, 3, e001000. [CrossRef]

50. Chen, L.; Wu, Q.; Guo, F.; Xia, B.; Zuo, J. Expression of Dishevelled-1 in wound healing after acute myocardial infarction: Possible involvement in myofibroblast proliferation and migration. J. Cell. Mol. Med. 2004, 8, 257-264. [CrossRef]

51. Ueland, T.; Otterdal, K.; Lekva, T.; Halvorsen, B.; Gabrielsen, A.; Sandberg, W.J.; Paulsson-Berne, G.; Pedersen, T.M.; Folkersen, L.; Gullestad, L.; et al. Dickkopf-1 enhances inflammatory interaction between platelets and endothelial cells and shows increased expression in atherosclerosis. Arterioscler. Thromb. Vasc. Biol. 2009, 29, 1228-1234. [CrossRef] [PubMed]

52. Babuin, L.; Jaffe, A.S. Troponin: The biomarker of choice for the detection of cardiac injury. Can. Med. Assoc. J. 2005, 173, 1191-1202. [CrossRef] [PubMed]

53. Gaggin, H.K.; Januzzi, J.L., Jr. Natriuretic peptides in heart failure and acute coronary syndrome. Clin. Lab. Med. 2014, 34, 43-58. [CrossRef]

54. Kohchi, C.; Noguchi, K.; Tanabe, Y.; Mizuno, D.; Soma, G. Constitutive expression of TNF-alpha and -beta genes in mouse embryo: Roles of cytokines as regulator and effector on development. Int. J. Biochem. 1994, 26, 111-119. [PubMed]

55. Dick, S.A.; Epelman, S. Chronic Heart Failure and Inflammation: What Do We Really Know? Circ. Res. 2016, 119, 159-176. [CrossRef] [PubMed]

56. Iwamatsu, T. Stages of normal development in the medaka Oryzias latipes. Mech. Dev. 2004, 121, 605-618. [CrossRef] [PubMed]

57. Fujita, M.; Isogai, S.; Kudo, A. Vascular anatomy of the developing medaka, Oryzias latipes: A complementary fish model for cardiovascular research on vertebrates. Dev. Dyn. 2006, 235, 734-746. [CrossRef] [PubMed]

58. Gonzalez-Doncel, M.; Okihiro, M.S.; Torija, C.F.; Tarazona, J.V.; Hinton, D.E. An artificial fertilization method with the Japanese medaka: Implications in early life stage bioassays and solvent toxicity. Ecotoxicol. Environ. Saf. 2008, 69, 95-103. [CrossRef]

59. Kais, B.; Schneider, K.E.; Keiter, S.; Henn, K.; Ackermann, C.; Braunbeck, T. DMSO modifies the permeability of the zebrafish (Danio rerio) chorion-implications for the fish embryo test (FET). Aquat. Toxicol. 2013, 140-141, 229-238. [CrossRef]

60. McCurley, A.T.; Callard, G.V. Characterization of housekeeping genes in zebrafish: Male-female differences and effects of tissue type, developmental stage and chemical treatment. BMC Mol. Biol. 2008, 9, 102. [CrossRef]

61. Li, M.Y.; Tang, Y.H.; Liu, X.; Lu, H.Y.; Shi, X.Y. Sensitive determination of 4-O-methylhonokiol in rabbit plasma by high performance liquid chromatography and application to its pharmacokinetic investigation. J. Pharm. Anal. 2011, 1, 108-112. [CrossRef]

62. Poivre, M.; Duez, P. Biological activity and toxicity of the Chinese herb Magnolia officinalis Rehder \& E. Wilson (Houpo) and its constituents. J. Zhejiang Univ. Sci. B 2017, 18, 194-214. [PubMed]

Sample Availability: Samples of the compounds are not available from the authors. 